Review Article

\title{
Hepigenetics: A Review of Epigenetic Modulators and Potential Therapies in Hepatocellular Carcinoma
}

\author{
Mohamed H. Yousef $\left(\mathbb{D},{ }^{1}\right.$ Hassan A. N. El-Fawal $\mathbb{D}^{2},{ }^{2}$ and Anwar Abdelnaser $\mathbb{D}^{2}$ \\ ${ }^{1}$ Biotechnology Graduate Program, School of Science and Engineering, The American University in Cairo, Cairo, Egypt \\ ${ }^{2}$ Institute of Global Health and Human Ecology, School of Science and Engineering, The American University in Cairo, Cairo, Egypt \\ Correspondence should be addressed to Anwar Abdelnaser; anwar.abdelnaser@aucegypt.edu
}

Received 11 August 2020; Revised 13 October 2020; Accepted 5 November 2020; Published 24 November 2020

Academic Editor: Junyan Tao

Copyright ( 2020 Mohamed H. Yousef et al. This is an open access article distributed under the Creative Commons Attribution License, which permits unrestricted use, distribution, and reproduction in any medium, provided the original work is properly cited.

\begin{abstract}
Hepatocellular carcinoma is the fifth most common cancer worldwide and the second most lethal, following lung cancer. Currently applied therapeutic practices rely on surgical resection, chemotherapy and radiotherapy, or a combination thereof. These treatment options are associated with extreme adversities, and risk/benefit ratios do not always work in patients' favor. Anomalies of the epigenome lie at the epicenter of aberrant molecular mechanisms by which the disease develops and progresses. Modulation of these anomalous events poses a promising prospect for alternative treatment options, with an abundance of felicitous results reported in recent years. Herein, the most recent epigenetic modulators in hepatocellular carcinoma are recapitulated on.
\end{abstract}

\section{Introduction}

Hepatocellular carcinoma (HCC) is a notoriously aggressive cancer with high global prevalence rates and is the next most common perpetrator of cancer-related death following pulmonary carcinomas, with annual mortality rates of the order of 800,000 deaths [1]. HCC develops in a backdrop of a chronic liver disease that ultimately results in liver fibrosis and cirrhosis, which are consequential HCC risk factors. Hepatitis C and B, aflatoxins, alcoholic liver disease, and nonalcoholic steatohepatitis are all commonly encountered chronic inflammatory hepatopathologies that predispose to HCC. Depending on the etiology, disparate molecular dysregulation patterns arise, all converging on promoting malignancy. The loss of cell cycle restraints, incapacity to senesce, and disarrayed apoptosis [2] are among such dysregulated mechanisms, which could well be the result of genetic as well as epigenetic alterations.

The epigenome constitutes heritable features of the genetic material out with the DNA sequence. Specific epigenetic patterns are important for the maintenance of cellular integrity and gene expression patterns associated with health. In this capacity, the epigenetic fingerprint functions to guarantee proper and timely expression of genetic information, and its alteration aggravates pernicious cellular changes, many of which predispose to cancer [3]. Herein, a compendium of the most recent work addressing epigenetic modulators in the context of HCC is presented.

1.1. What Is Epigenetics? Epigenetics is a term that was first coined by Conrad Waddington, and it literally means "above genetics" [4]. It entails changes to cellular phenotypes, which are not dependent on alterations of the genetic code (DNA sequence). However, unanimity regarding the definition of epigenetics has thus far been elusive, and debates in this regard have been inconclusive at best [5].

As previously mentioned, the most recognized of epigenetic mechanisms involve chromatin remodeling. Chromatin is the macromolecule by virtue of which the genetic material can be packed inside cells' nuclei. It is composed of nucleosomes: DNA wound around histone protein octamers. In its compact form, the heterochromatin, the genetic material is relatively inaccessible for replication and the genes within are largely silent. The euchromatin on the other hand is a relaxed form of chromatin where the DNA is more accessible and genes are more or less actively expressed [5]. It can thus be easily concluded that regulation of chromatin condensation plays a role in regulating gene expression and the 
resulting phenotypes. Chromatin-modifying enzymes are key players in effecting such restructuring and subsequent modifications to DNA and the histone scaffolding on which it is wound.

CpG islands are clusters of $\mathrm{CpG}$ dinucleotides predominantly found in the promoter regions of genes. Generally, methylation of the 5-carbon in the cytosine of these $\mathrm{CpG}$ islands shields the promoter from the transcription machinery to the end result of a controlled gene expression. On the other hand, demethylation of these regions within gene promoters allows for the recruitment of the transcription machinery and the gene is essentially "on." Such functionality is predominantly reserved for DNA methyltransferases. That being said, promoters containing CpG islands account for only $70 \%$ of the promoters in the genome. Interaction with the remaining $30 \%$ is orchestrated by modifications to the histone proteins, regulated - to a large extent-by histone deacetylases [5]. The disruption of these mechanisms can thus lead to aberrations in gene expression, which in many cases can initiate or promote oncogenesis. For example, the promoters of genes, which are normally turned off, are usually found hypomethylated in cancer.

1.2. Epigenetic Modulators. Options for epigenetic therapies in HCC can be enumerated as follows: inhibitors of DNA methyltransferases, regulators of histone methyltransferases, demethylases, acetyltransferases, and-most prominentlydeacetylases. Another major class of epigenetic modulators is represented in noncoding RNAs. Below, the most eminent and clinically established classes are explored comprehensively to afford an encyclopedic overview of the current status of epigenetic recourse for HCC therapy. However, due to scarcity of data, several agents such tacedinaline, romidepsin, some helicases, and other enzymes viz. acireductone dioxygenase 1 are not discussed.

\section{DNA Modifications}

2.1. DNA Methyltransferases (DNMTs). The implication of epigenetic changes in HCC, specifically aberrant patterns of DNA methylation, has recently been recognized as a primary contributor to disease onset and progression [6]. As a consequence of such epigenetic anomalies, key tumor suppressors may be silenced or oncogenes activated, resulting in the initiation of tumorigenesis. DNA methylation is mediated by a conserved class of catalytic proteins known as DNA methyltransferases (DNMTs). DNMTs are key players of the epigenome. DNMTs come in two primary categories, maintenance (DNMT1) and de novo DNMTs (DNMT3a and DNMT3b) [7]. Although the distinction is not absolute, it does hold contemporarily. DNMT1, DNMT3a, and DNMT3b function by catalyzing the transfer of a methyl group from S-adenosyl-L-methionine, the universal methyl donor to a $5^{\prime}$-cytosine on DNA [8]. Moreover, several other DNMTs do exist (such as DNMT2 and DNMTL); however, they remain relatively undefined despite having demonstrated a role in HCC [9].

Despite the widely suggested distinction that DNMT1 functions as the maintenance methyltransferase and DNMT3a and DNMT3b mediate de novo methylation (predominantly during embryonic development), the notion has been challenged as of late, with DNMT1 recognized as a contributor to de novo methylation while maintenance functions are mediated by DNMT3a and DNMT3b in concert with DNMT1 [10]. Notwithstanding the above-mentioned classification, these enzymes do not function individually and their interaction is crucial to the creation and maintenance of appropriate methylation patterns. The alteration of such coordination has in fact been associated with cancer development [11].

2.2. DNMT1. DNMT1 is the most common subtype in adult cells [12]. Normally, DNMT1 functions to maintain methylation patterns of $\mathrm{CpG}$ sites within promoters. This is achieved by DNMT1 accessing hemi-methylated DNA during replication, priming the daughter unmethylated strand for methylation. However, anomalous DNMTmediated methylation jeopardizes typical gene expression patterns as a result of increased or decreased accessibility of CpG-rich promoters. HCC and its adjacent tissues have demonstrated notably different DNA methylation patterns [6]. Where the noncancerous neighboring tissues display uniform and stable methylation patterns, HCC exhibits a marked heterogeneity. According to the reported results, HCC tissues manifest reduced methylation of $\mathrm{CpG}$ regions. Table 1 shows a snippet of the reported signature of methylated genes in HCC, which is reportedly capable of differentiating HCC samples from neighboring tissues. A former study showed that DNA methylation of CpG island-associated promoters silenced gene expression and defined 222 drivers of epigenetic changes exhibiting this negative correlation. A preponderance of these candidate drivers was found to be enriched in inflammatory responses, a number of metabolic processes, and oxidation-reduction reactions. A set of reliable and robust candidates was also defined (Table 1).

Neurofilament, heavy polypeptide (NEFH) and sphingomyelin phosphodiesterase 3 (SMPD3) were also defined as tumor suppressor genes that were hypermethylated and silenced in HCC [13]. The results obtained from the gain of function experiments revealed diminished cellular proliferation, whereas those of knockdowns restored tumor invasiveness and migratory capacities. Conversely, hypomethylation of the fetal promoters of the oncogene, IGF2, gave way to its overexpression, imparting virulent phenotypes [14]. DNA methylation has also been inculpated in the dysregulation of several long noncoding RNAs (lncRNAs), which have been awhile associated with HCC. The histone methyltransferase enhancer of zeste homolog 2 (EZH2), which catalyzed the trimethylation at lysine 27 of histone $\mathrm{H} 3$, has been proven to silence TCAM1P-004 and RP11-598D14.1: two tumorsuppressing long noncoding RNAs [15]. This has been supposed to be assisted by Yin Yang 1 (YY1), which purportedly aids in recruiting EZH2 to promoters of target genes [16]. The downregulation of these IncRNAs correlated with tumor progression owing to the inhibition of their moderation of the mitogen-activated protein kinase (MAPK), tumor protein p53 (p53), and hypoxia-inducible factor 1-alpha (HIF1- $\alpha)$ pathways [15]. As would be expected, upregulation of histone methyltransferases might just be the driver for neoplastic 
TABle 1: Aberrant methylation patterns in hepatocellular carcinoma (HCC). A comprehensive list of genes, which were dysregulated in HCC due to aberrant methylation patterns.

\begin{tabular}{|c|c|c|}
\hline Gene & Methylation pattern & Ref. \\
\hline ACSL4 & Hypomethylation & \multirow{4}{*}{ [217] } \\
\hline$A L D H 3 A 1$ & Hypomethylation & \\
\hline APOA5 & Hypermethylation & \\
\hline CLDN15 & Hypomethylation & \\
\hline$C D K N 2 A$ & Hypermethylation & {$[6]$} \\
\hline CYP7A1 & Hypomethylation & [217] \\
\hline DEFB119 & Hypomethylation & \multirow{3}{*}{ [6] } \\
\hline$D P P 6$ & Hypomethylation & \\
\hline ENDOD1 & Hypermethylation & \\
\hline$E Z R$ & Hypermethylation & \multirow[t]{2}{*}{ [217] } \\
\hline GLUL & Hypomethylation & \\
\hline$G Z M B$ & Hypomethylation & {$[6]$} \\
\hline MIR21 & Hypomethylation & [218] \\
\hline Myolg & Hypermethylation & [219] \\
\hline NEFH & Hypermethylation & {$[13]$} \\
\hline NKX3-2 & Hypermethylation & \multirow{3}{*}[6]{} \\
\hline NDRG2 & Hypermethylation & \\
\hline PDE1A & Hypomethylation & \\
\hline PHYHD1 & Hypermethylation & [217] \\
\hline PRH2 & Hypermethylation & {$[6]$} \\
\hline RASSF1A & Hypermethylation & [220] \\
\hline RP11-598D14.1 & Hypermethylation & {$[15]$} \\
\hline SCAND3 & Hypermethylation & [219] \\
\hline$S P P 1$ & Hypomethylation & [217] \\
\hline SPRR2A & Hypomethylation & {$[6]$} \\
\hline SLC25A47 & Hypermethylation & {$[6]$} \\
\hline SLC25A47 & Hypermethylation & [217] \\
\hline SLC39A12 & Hypomethylation & {$[6]$} \\
\hline SMPD3 & Hypermethylation & {$[13]$} \\
\hline SFN & Hypomethylation & [217] \\
\hline$S G C A$ & Hypomethylation & \multirow{2}{*}[6]{} \\
\hline TBX4 & Hypermethylation & \\
\hline TCAM1P-004 & Hypermethylation & {$[15]$} \\
\hline TKT & Hypomethylation & [217] \\
\hline VTRNA2-1 & Hypermethylation & [221] \\
\hline$Z P B P$ & Hypermethylation & {$[6]$} \\
\hline
\end{tabular}

ACSL4: Acyl-CoA Synthetase Long Chain Family Member 4; ALDH3A1: Aldehyde Dehydrogenase 3 Family Member A1; APOA5: Apolipoprotein A5; CLDN15: Claudin-15; CDKN2A: cyclin-dependent kinase inhibitor 2A; CYP7A1: Cytochrome P450 Family 7 Subfamily A Member 1; DEFB119: Defensin $\beta$ 119; DPP6: Dipeptidyl peptidase 6; ENDOD1: Endonuclease Domain Containing 1; EZR: Ezrin; GLUL: Glutamate-Ammonia Ligase; GZMB: Granzyme B; MIR21: microRNA-21; Myolg: Myosin 1g; NDRG2: $\mathrm{N}$-myc downstream-regulated gene family member 2; NEFH: Neurofilament, heavy polypeptide; NKX3-2: NK3 Homeobox 2; PDE1A: Phosphodiesterase 1A; PHYHD1: Phytanoyl-CoA Dioxygenase Domain Containing 1; PRH2: Proline-rich protein HaeIII subfamily 2; RASSF1A: Ras association domain family 1 isoform A; SCAND3: SCAN domain containing 3; SFN: Stratifin; SGCA: $\alpha$-sarcoglycan; SLC25A47: Solute Carrier Family 25 Member 47; SLC39A12: Solute carrier family 39 member 12; SMPD3: sphingomyelin phosphodiesterase 3; SPP1: Secreted Phosphoprotein 1; SPRR2A: Small proline-rich protein 2A; TBX4: T-box 4; TKT: Transketolase; VTRNA2-1: Vault RNA 2-1; ZPBP: Zona pellucida binding protein. events, given their downstream action on key promoters. By way of instance, SET domain bifurcated histone lysine methyltransferase 1 (SETDB1), an H3K9-specific methyltransferase, has been reported to exhibit the most substantial increase in HCC in comparison to other epigenetic regulators [17]. SETDB1 was shown to owe its overexpression in HCC to a gene duplication event, with an additional copy of chromosome 1q21 [17]. However, other anomalous events were discovered to contribute to its elevated levels, such as regulation by microRNAs (discussed below), or transcriptional activation such as this mediated by specificity protein 1 (SP1) [17].

\subsection{DNMT3. Contrary to DNMT1, DNMT3a and DNMT3b} do not recognize hemimethylated DNA. They do not produce or maintain particular patterns of methylation [18], and they are not specifically associated with replication sites [19] as DNMT1. Rather, they mediate de novo methylation as mentioned previously. Additionally, it has been assumed that these DNMTs employ mechanisms different from DNMT1 to access the heterochromatin [20], given the fact that they were found not to be associated with replication sites.

DNMT3 has been implicated in hepatocarcinogenesis. It has been expressly associated with hypermethylation of promoters controlling 22 tumor suppressor genes [21]. $D N M T 3 b$ also exhibited a 4 -fold increase of expression in HCC when compared to healthy livers, which correlated with poorer prognosis [21], which corroborates assumptions that DNMT3 subtypes become overexpressed in cancer after having been downregulated postcellular differentiation [22].

In HCC of HBV etiology, the normally silenced metastasis-associated protein 1 (MTA1) gene was upregulated by recruitment of DNMT3a and DNMT3b leading to hypomethylation of its promoter and increasing the tumor metastatic disposition [23]. Additionally, DNMT3b was elsewhere reported to be overexpressed by telomerase reverse transcriptase (TERT) in HCC. The resulting anomalous methylation patterns prompted activation of $A K T$ [24]. Apart from its methylating capacity, $D N M T 3 b$ was found to directly target metastasis suppressor 1 (MTSS1), by direct binding to its promoter [25].

The implication of DNMT3a in HCC has also been corroborated. In a study by Zao et al., DNMT3a knockdowns displayed arrested cellular proliferation. Microarray analysis revealed concomitant upregulation of 153 genes, the preponderance of which bears $\mathrm{CpG}$ islands in their promoters. Among these activated genes was the tumor suppressor PTEN gene [26]. Moreover, DNMTa guided a conjectured distinction in the epigenetic dysregulation between different forms of liver cancer, where nonfibrolamellar HCC displayed significantly higher levels of DNMTa compared to the fibrolamellar variant [27]. This discrepancy was suggested to betray divergent epigenetic mechanisms in different HCC subtypes.

2.4. DNMT3L. Structurally similar and functionally complementary to DNMT3a and DNMT3b is DNMT3L, which, despite lacking intrinsic catalytic activity, enhances the binding of the former to S-adenosyl-L-methionine, the donor of 
TABLE 2: DNA methyltransferase (DNMT) inhibitors in HCC. The table shows the most prominent DNMT inhibitors, the changes in the targets of the inhibited DNMTs, and the resulting effects on the tumor.

\begin{tabular}{|c|c|c|c|}
\hline DNMT inhibitor & DNMT targets affected & Effect & Ref. \\
\hline 5-Azacytidine & SLC10A1, CYP3A4, ALB, and miR-122 & Inhibits tumor growth & [29] \\
\hline \multirow{2}{*}{ Decaitabine } & p16INK4A (activation) & G1 cell cycle arrest & [35] \\
\hline & PRSS3 (activation) & Inhibits proliferation and migration & [36] \\
\hline Guadecitabine (SGI-110) & $D L E C 1, R U N X 3$, and $p 16 I N K 4 A$ & Inhibits tumor growth & [38] \\
\hline Zebularine & $\begin{array}{l}C D K 2, B c l-2 \text {, and phosphorylation of } R b \text { (inhibition) and } \\
\qquad 21 W A F / C I P 1 \text { and } p 53 \text { (activation) }\end{array}$ & Inhibits proliferation and induces apoptosis & {$[42]$} \\
\hline SGI-1027 & $B c l-2$ (inhibition) and $B A X($ activation $)$ & Induces apoptosis & {$[222]$} \\
\hline $\mathrm{CM}-272$ & $\begin{array}{c}\text { E-cadherin, CYP7A1, FBP1, GNMT, and } \\
\text { MAT1A (activation) }\end{array}$ & $\begin{array}{l}\text { Inhibits proliferation and decreases } \\
\text { adaptation to hypoxia }\end{array}$ & {$[223]$} \\
\hline EGCG (Y6) & $P-g p$ and HIF1- $\alpha$ (inhibition) & $\begin{array}{l}\text { Inhibits proliferation and reverses } \\
\text { doxorubicin-resistance }\end{array}$ & {$[53]$} \\
\hline Genistein & $\begin{array}{c}C Y P 1 A 1, C Y P 1 B 1 \text {, and } p-A M P K \text { (activation) and } C Y P 26 A 1 \\
\text { and CYP26B1 (inhibition) }\end{array}$ & $\begin{array}{l}\text { Inhibits proliferation (at a } 10-40 \mu \mathrm{M} \\
\text { concentration) and induces apoptosis }\end{array}$ & [44] \\
\hline
\end{tabular}

ALB: albumin; BAX: Bcl-2-like protein 4; Bcl-2: B-cell lymphoma 2; CDK2: cyclin-dependent kinase 2; CYP1A1: cytochrome P450 1A1; CYP1B1: cytochrome P450 1B1; CYP26A1: cytochrome P450 26A1; CYP26B1: cytochrome P450 26B1; CYP3A4: cytochrome P450 3A4; CYP7A1: cholesterol 7 $\alpha$-hydroxylase-1; DLEC1: deleted in lung and esophageal cancer 1; FBP1: fructose-1,6-bisphosphatase; GNMT: glycine-N-methyl transferase; HIF1- $\alpha$ : hypoxia-inducible factor 1- $\alpha$; MAT1A: methionine-adenosyltransferase 1A; p16INK4A: cyclin-dependent kinase inhibitor 2A; $p 21 W A F / C I P 1$ : cyclin-dependent kinase inhibitor 1; p53: tumor protein p53; $p$-AMPK: phosphorylated AMP-activated protein kinase; P-gp: P-glycoprotein 1; Rb: retinoblastoma; RUNX3: RUNX Family Transcription Factor 3; SLC10A1: sodium/bile acid cotransporter.

the methyl group. Understanding the role of DNMT3L in full requires further analysis [28].

Given all of the above, it is clear that modifying any of these anomalies could potentially serve as a therapeutic modality in HCC. Below the major DNMT inhibitors with reported activity in HCC are outlined.

2.5. DNMT Inhibitors. Herein, the most prominent inhibitors of DNMT in HCC are outlined. Despite the fact that-in many instances-DNMT inhibitors may not be selective for one subtype over the other, the following is reported according to what the original account relayed. DNMT inhibitors are summarized in Table 2.

2.6. 5-Azacytidine. 5-Azacytidine (5-AZA) is a synthetic ana$\log$ of the nucleoside cytidine and an established inhibitor of DNMT1, marketed under the name Vidaza. In the context of HCC, treatment with 5-AZA conduced to tumor regression and a shift to a more differentiated phenotype, which was associated with regional demethylation of $\mathrm{CpG}$ regions upstream of the liver-specific genes SLC10A1, CYP3A4, $A L B$, and $m i R-122$, which were downregulated pretreatments [29]. Additionally, this epigenetic modulation boosted the effects of sorafenib. 5-AZA triggered demethylation of 5hydroxymethylcytosine $(5 \mathrm{hmC})$ via the ten-eleven translocation proteins 2 and 3 [30]. DNMT1 inhibition by 5-AZA was also found to synergize with immunotherapy via encouraging trafficking of T-cells to the tumor microenvironment secondary to a 5-AZA-induced upregulation of chemokine genes [31]. 5-AZA has been determined to be potentiated by sundry supplementation, such as vitamin C [32] and alendronate [33]. More recently, 5-aza-2' -deoxycytidine (5-AzaCdR), a derivative of 5-AZA, was reported to downregulate DNMT1, DNMT3a, and DNMT3b [34].
2.7. Decitabine. Decitabine (5-aza- $2^{\prime}$-deoxycytidine) is another analog of cytidine that also acts by blocking DNMT1. Decitabine was reported to demethylate the promoter of the p16INK4A gene, the product of which functions to regulate the cyclin-dependent kinases 4 and 6, leading to an upsurge of p16INK4A transcripts with ensuing G1 cell cycle arrest and a rise of the senescence-associated $\beta$-galactosidase [35]. Expression levels of PRSS3 were also reported to rise in decitabine-treated cells [36]. The desilencing of PRSS3 decelerated cellular proliferation due to inhibition of two cyclin/CDK complexes and downshifted migration through silencing matrix metalloproteinase 2 (MMP2). A phase I/II clinical trial [37] scrutinized the efficacy of decitabine and its safety in advanced HCC. Western blots from patients' peripheral blood mononuclear cells (PBMCs) indicated decreased levels of DNMT1 in decitabine-treated participants.

2.8. Guadecitabine. Guadecitabine is a dinucleotide derivative of decitabine in which the latter is attached to a deoxyguanosine is by a phosphodiester bridge. Guadecitabine is commonly designated as SGI-110 and exhibits a more sustained systemic effect than its parent compound. Demethylation and activation of the tumor suppressor genes DLEC1, RUNX3, and CDKN2A were observed following SGI-110 treatment of Huh7 and HepG2 cells. Although its demethylating effects were compromised in the presence of the histone $\mathrm{H} 2 \mathrm{~A}$ variant, macroH2A1, SGI-110 was still capable of restricting tumor growth, unlike decitabine [38]. Potentiation of the cytotoxicity of the platinum-based antineoplastic oxaliplatin was reported when a pretreatment of SGI-110 was coadministered [39]. The mechanistic basis of such a sensitization involves counteracting the extensive methylation of targets within the Wnt/EGF/IGF signaling loop. 
2.9. Zebularine. In HepG2 cells cultured at high densities, zebularine, a more stable and less toxic analog of 5-AZA [40], demonstrated a progressive escalation of expression of differentiation-associated genes and fomented apoptosis. shRNA-induced DNMT1 knockdown annulled these effects [41]. Paradoxically, contrary reports indicated that zebularine had negligible influence on DNA methylation in the same cell line [42]. Despite the previous report, zebularine did affect several cytotoxic events, which have been attributed to mechanisms other than DNMT inhibition. Zebularine was found to inhibit histone deacetylases (HDACs) alongside DNMT genes in LS 174T cells [43]. DNMT1, DNMT3a, and DNMT3a as well as Class I HDACs and Class II HDACs were downregulated with a concomitant elevation in the expression of $p 21$ Cip1/Waf1/Sdi1, p27Kip1, and p57Kip2 on treatment with zebularine, albeit to a more modest extent in comparison with trichostatin A. In the same study, it was observed that both agents acted synergistically to substantially increase apoptosis. It would thus seem propitious to examine these regulatory loops more closely in HCC.

2.10. Genistein. Genistein (GE) is an isoflavone derived from soybean and is characterized by its propensity to bind the estrogen receptor. GE upregulated cytochromes $1 A 1$ and $1 B 1$ in HT29 cells and downregulated cytochromes $26 \mathrm{~A} 1$ and $26 B 1$ [44]. In Hep3B cells, GE increased levels of phospho- $A M P K$, which mitigated inflammatory processes and consequent liver damage [45]. In concert with trichostatin A (TSA), GE restored the expression of the DNA methyltransferases DNMT1, DNMT3a, and DNMT3b in HepG2 cells [46]. GE exhibited biphasic effects at different concentration ranges, where at a low concentration of $1 \mu \mathrm{M}$, it encouraged cellular growth, while at higher concentration within the range of $10-40 \mu \mathrm{M}, \mathrm{GE}$ had antiproliferative effects. Proapoptotic effects were evident at all concentrations, unlike TSA, whose effects were observable only following a 3-day long treatment [47].

2.11. Epigallocatechin-3-Gallate (EGCG). EGCG is the most abundant catechin in green tea that-among other flavonoids and catechins-has repeatedly been reported to possess tumor chemopreventive and antineoplastic effects in HCC [48]. EGCG has been shown to interact with the following amino acid residues within the catalytic domain of DNMT: P-1223, C-1225, S-1229, E-1265, and R-1309 [49, 50]. Moreover, catechol-containing polyphenols, of which EGCG is a member, inhibit DNMTs by mediating a rise in SAM O-methylation via catechol-O-methyltransferase. Alternatively, SAM levels were increased following disruption of the folate cycle secondary to dihydrofolate reductase inhibition by catechol-containing polyphenols. Direct inhibition of DNMTs by this class of compounds can also occur regardless of the methylation pattern $[49,50]$.

Additionally, EGCG has been shown to mediate a metabolic shift away from glycolysis in HCC cells, thereby promoting apoptosis and stunting cellular proliferation [51]. Mechanistically, this action has been attributed to its suppression of phosphofructokinase activity, whereby cellular stress is effected, ultimately culminating in programmed cell death. What is more, EGCG synergistically acted to ameliorate the antiproliferative effects of sorafenib [51]. Synergy between EGCG and metformin, the famous antidiabetic biguanide, has also been reported [52]. An EGCG/metformin combination therapy was associated with a significant reduction in glypican-3, survivin, cyclin D1, VEGF, and the long noncoding RNA AF085935 and an elevation of the levels of caspase 3 [52]. Another study examined the therapeutic effects of Y6, a chemically modified form of EGCG [53]. Again, and similar to its parent compound, Y6 efficiently curbed cellular proliferation. Additionally, it engendered a reversal of doxorubicin resistance in resistant BEL-7404 cells. The antiproliferative and antiapoptotic effects of Y6 correlated with reduced $P$-glycoprotein $1(P-g p)$ and HIF1- $\alpha$ on the mRNA and protein levels and was exacerbated in groups receiving Y6/doxorubicin combination therapy, compared to those on doxorubicin monotherapy. A compendium of studies reporting disease-modifying capabilities of EGCG in HCC can be found in a recent review by Bimonte et al. [48].

Other inhibitors of DNMT such as hydralazine, procainamide, and RG108 have been tested for their efficacy in cancer [11] but are yet to be examined as potential therapies in HCC.

\section{Histone Modifications}

Chromatin is formed by the assembly of nucleosomal units, which are formed by the wounding of DNA around histone proteins. For accessing of genetic information, the highly packed chromatin has to be unwound. Chromatin modifications viz. methylation and acetylation are key controllers of this stipulation and thus play a crucial role in gene expression (Figure 1).

Histone modifications comprise sundry alterations to histone proteins including methylation (histone methyltransferases and histone demethylases), acetylation (histone acetyltransferases and histone deacetylases), ubiquitination, sumoylation, and phosphorylation [54]. The disruption of any of these modification patterns entails repercussions that may very well conduce to malignancy. However, for the purpose of this review, we elected to center this discourse on histone deacetylases (HDACs) given the abundance of data and the corroborated efficiency of HDAC inhibitors in preclinical and clinical settings [55]. Other reviews can be consulted for in-depth discussion of histone modifications and their implications in cancer [56-59].

Histone acetylation is controlled by two classes of enzymes: histone acetyltransferases (HATs) and histone deacetylases (HDACs). HATs catalyze the acetylation of lysine residues, whereas HDACs function to remove these acetyl groups [60].

As a result of acetylation, interaction between the histone octamers and DNA is compromised due to the neutralization of the positively charged lysine residues. The weakening of this interaction gives way to a transcriptionally permissive state of chromatin. HDACs promote an opposite effect, where the euchromatin state is favored as a consequence of retrieval of the positive charges on lysine residues, restoring the histone-DNA interaction [61]. A balance between HAT 


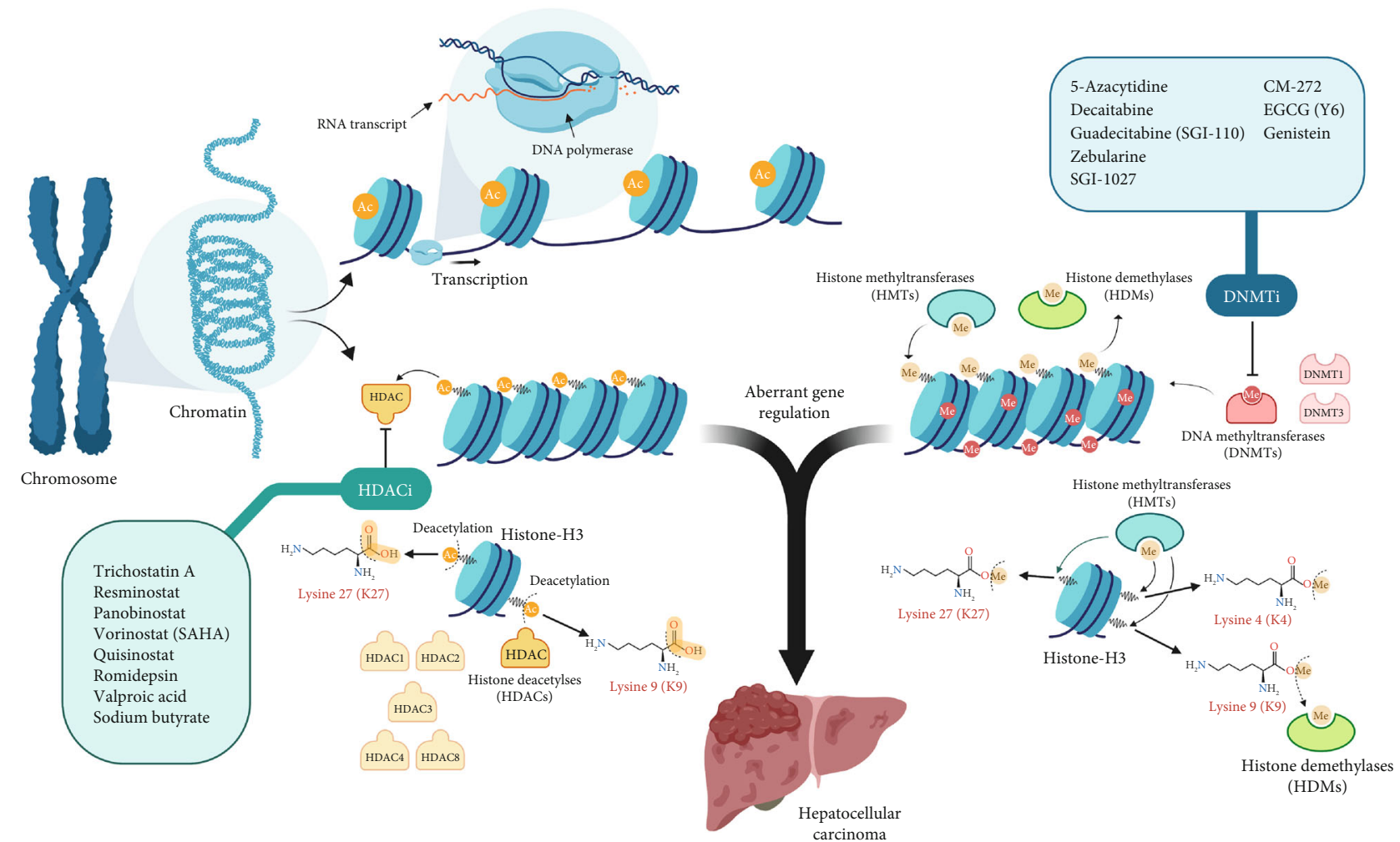

FIGURE 1: Epigenetic modulation of chromatin by histone deacetylation and methylation/demethylation as well as DNA methylation. The figure highlights the role of histone deacetylases (HDACs), histone methyltransferase (HMTs), histone demethylases (HDMs), and DNA methyltransferases (DNMTs) in creating the epigenetic signature observed in HCC in addition to their significance as targets for therapy. As is shown, the most common site for such modifications occurs on specific lysine residues on histone H3. "Created with BioRender."

and HDAC activity ensures the maintenance of normal patterns of gene expression, and its disruption is often noted in many malignancies including HCC [62].

3.1. HDACs. There are around 18 HDACs, many of which have been shown to deacetylate nonhistone proteins [63]. Given the above, the centrality of HDACs to chromatin accessibility and control of gene expression [64] is obvious, and assumptions that HDACs constitute tumor suppressors or target for therapy are not only well-grounded but also experimentally evident.

In HCC, dysregulation of HDACs has been multiplied reported. By way of instance, HDAC1 and HDAC2 were found to be overexpressed in HCC patients of Southeast Asian origin and was associated with higher rates of mortality. Inhibition of these HDACs in vitro inhibited cellular proliferation [65]. The upregulation of HDAC1 and HDAC2 was found to suppress fructose-1,6-bisphosphatase (FBP1), a key enzyme in glycolysis [66], and HDAC2 was further reported to modulate genes involved in the cell cycle and apoptosis [67]. HDAC3 was recently demonstrated to be centrally implicated in hepatocarcinogenesis. Following a ubiquitination event, it dissociates from the $c-M y c$ promoter, whereby $\mathrm{K} 9$ of histone $\mathrm{H} 3$ (H3K9) becomes acetylated and $c-M y c$ is made transcriptionally available [68]. Elimination of $H D A C 3$ inhibited the trimethylation of $\mathrm{H} 3 \mathrm{~K} 9$ that occurs subsequent to the HDAC3-mediated deacetylation of this residue, arrest- ing the contingent double-strand break repair mechanism and resulting in the accretion of bad DNA [69].

Interestingly, HDACs were also shown to counter cell migration. Acetylation of $\mathrm{H} 3 \mathrm{~K} 4$ and $\mathrm{H} 3 \mathrm{~K} 56$ within the Snail2 promoter was markedly reduced in EMT thanks to HDAC1 and HDAC3 [70]. It is worthy to note that G9a, a histone $\mathrm{H} 3$ lysine 9 (H3K9) methyltransferase, has been recently recognized as vital for such Snail2-mediated inhibition of E-cadherin and consequent repression of mesenchymal properties [71]. It has even been targeted for therapy by administering its inhibitor, UNC0646, in nanodiamonds, which reduced $\mathrm{H} 3 \mathrm{~K} 9$ methylation and tumor invasiveness [72].

That being said, therapeutic inhibition of HDACs may sometimes prove problematic because of interference with various pathways [56] and, as evident above, for the bidirectional functionality it has sometimes demonstrated. It is thus of essence to dedicate some efforts to better understand and characterize the complex regulatory role of HDACs so as to determine their amenability to therapeutic targeting and define in what direction should therapeutic strategies be pursued.

3.2. HDAC Inhibitors. HDAC inhibitors (HDACi) are a group of agents that are useful in resolving aberrant patterns of deacetylation, modulating chromatin accessibility, the lack of which is often an inciting factor for tumorigenesis [73]. Below the most prominent HDACis are outlined (Table 3 ). 
TABLE 3: Histone deacetylase (HDAC) inhibitors in HCC. The table shows the most prominent HDAC inhibitors that have been studied in HCC, their cellular targets, and their antitumor effects.

\begin{tabular}{|c|c|c|c|}
\hline \multicolumn{4}{|c|}{ Hydroxamates } \\
\hline HDACi & Target(s) & Effect & Ref. \\
\hline \multirow{2}{*}{ Trichostatin A } & Apaf1 and $H 2 A u b$ (activation) & Promotes apoptosis & {$[74]$} \\
\hline & $U L B P 1 / 2 / 3$ and $M I C A / B$ (Activation) & Inhibits tumor cell growth & {$[77]$} \\
\hline Resminostat & Caspase 9 and cytochrome $c$ (activation) & $\begin{array}{l}\text { Promotes mitochondrial depolarization } \\
\text { and apoptosis }\end{array}$ & {$[80]$} \\
\hline Panobinostat & $\begin{array}{c}\text { Beclin1, Map1LC3B, and } p 53 \text { (activation) and } p 73 \\
\text { nuclear translocation }\end{array}$ & Promotes autophagy & {$[86]$} \\
\hline \multirow{2}{*}{ Vorinostat (SAHA) } & $H I F-\alpha($ inhibition $)$ & Initiating tumor hypoxia & {$[73]$} \\
\hline & DR5 (activation) and $c$-Flip (inhibition) & Sensitization to TRAIL-induced apoptosis & [224] \\
\hline Quisinostat ( \pm sorafenib) & $\begin{array}{c}\text { c-Caspase 3, c-Caspase 9, } c \text {-PARP, and Bax (activation) } \\
\text { and Bcl-xL,Bcl-2, survivin, PI3K-p110, PI3K-p85, and } \\
\text { p-AKT (inhibition) }\end{array}$ & Inducing G0/G1 phase arrest and apoptosis & [225] \\
\hline \multicolumn{4}{|c|}{ Cyclic peptides } \\
\hline Romidepsin & $p$-Erk and $p-J N K$ (activation) & $\begin{array}{l}\text { Induces cell cycle arrest in the G2/M phase } \\
\text { and apoptosis }\end{array}$ & {$[226]$} \\
\hline \multicolumn{4}{|c|}{ Aliphatic fatty acids } \\
\hline Valproic acid & Nrf2 (inhibition) & Sensitization to proton irradiation & {$[94]$} \\
\hline Valproic acid (+DOX) & AKT/mTOR (inhibition) & Increases ROS and induces autophagy & {$[95]$} \\
\hline Sodium butyrate & $p-A K T$ and $m T O R$ (inhibition) and $C Y L D$ (activation) & Increases ROS and induces autophagy & [99], [76] \\
\hline
\end{tabular}

\section{Hydroxamates}

4.1. Trichostatin A. TSA is one of the most studied hydroxamate HDAC inhibitors. Following inhibition of HDACs 1, 2, and 3 by TSA, apoptotic protease-activating factor 1 (Apaf1) was determined to become upregulated, which leads to the stimulation of mitochondrial caspase-driven apoptosis of the HLE and HLF HCC cell lines [74]. TSA was also found to restore the expression level of $\mathrm{H} 2 \mathrm{Aub}$, an $\mathrm{H} 2 \mathrm{~A}$ posttranslationally ubiquitinated at lysine 119 , which is diminished in HCC. Simultaneously, TSA modulated the rates of H3S10 phosphorylation, which were inversely correlated with H2Aub in HCC [75]. In addition to ubiquitin-specific peptidase 21 (ups21), which is responsible for the downregulation of H2Aub above, CYLD is another (lysine 63) deubiquitinase involved in the development of HCC. Contrary to Ups21, it is the inadequacy of CYLD that is associated with malignancy. TSA was shown to raise CYLD mRNA and protein levels in Huh7 and HepG2 cells [76]. Overexpression of ligands of NKGD2 was noted following TSA treatment. It thus exerted its cytotoxic effect through stimulating natural killer (NK) cells to eliminate HCC cells [77]. Alternatively, the proapoptotic activity of TSA could be modulated by regulatory RNA species such as the long noncoding RNA, $\operatorname{lncRNA-}$ uc002mbe.2, which was increased post-TSA-treatment [78]. The proposed mechanism delineates an interaction between IncRNA-uc002mbe.2 and heterogeneous nuclear ribonucleoprotein $A 2 B 1$ ( $h n R N P A 2 B 1)$ which instigates the stimulation of p21 and reduction of phosphorylated $A K T$. TSA has been used in conjunction with other agents such as sorafenib for enhancing therapeutic outcomes [79].

4.2. Resminostat. Resminostat is a pan-HDACi (inhibits both nuclear and cytoplasmic HDACs). In HepG2, SMMC-7721 and HepB3 cells, resminostat incited mitochondrial depolarization and apoptosis via the mitochondrial permeability transition pore pathway. It also evoked the production of caspase 9 and cytochrome $c$ [80]. The cytotoxic effects of resminostat were reinforced by inhibitors of the mammalian target of rapamycin ( $m$ TOR), which has been characterized as a resistance factor of resminostat [81]. The synergistic effects of resminostat with sorafenib have been repeatedly studied. The combination proved safe and effective. Resminostat shifted the cells from a mesenchymal to an epithelial phenotype, which better sensitized the cells to subsequent sorafenib treatment [82]. That being said, further investigation into the advantage of this combination is required. While an exploratory clinical study corroborates the above observations [83], another phase I/II study refuted an added utility of resminostat supplementation over sorafenib monotherapy [84].

4.3. Panobinostat (PANB). Another potent pan-HDACi is PANB. Studies have shown that PANB affected a negative interference with DNMTs (as outlined in Table 2) and an ensuing impedance of methylation of classically hypermethylated genes, such as APC and RASSF1A [85]. PANB encouraged an increase of autophagic factors Beclin1 and 
Map1LC3B, which concomitantly presented with the appearance of quasiautophagosome clusters along with the nuclear translocation of $p 53$ and p73 in HepG2 and Hep3B cells, respectively, and regulation of DRAM1 [86]. Ingeniously, ${ }^{18} \mathrm{~F}$ probes have been used as PET tracers to monitor angiogenic progression following PANB therapy, through imaging of integrin $\alpha v \beta 3$. These PET scans revealed a substantially reduced uptake in HepG2 but not in HT29 neoplasm, in response to therapy in nude mice [87].

4.4. Vorinostat (VORN; SAHA). Beyond chromatin unwounding, evidences have been provided that substantiate a role of VORN in initiating tumor hypoxia. Ostensibly, VORNmediated acetylation of heat shock protein 90 (Hsp90), a chaperone of $H I F-\alpha$, hinders its nuclear translocation and forestalls its transcriptional activity [73]. As a result, levels of several downstream hypoxia-triggered molecules come to be deficient. VORN was used as an adjuvant to a number of anticancer drugs such as oxaliplatin [88] and the $m$ TOR inhibitor, sirolimus [89]. Compared to 5-aza- $2^{\prime}$-deoxycytidine (5-AzaCdR), VORN exhibited superior apoptotic effects which was coincident with its inhibition of HDAC1. However, a combination of the two achieved maximal apoptosis of LCL-PI 11 cells [34].

4.5. Belinostat. Belinostat has been studied extensively but sporadically in different cancer types, mostly on hematologic malignancies. Despite its consistently promising results, belinostat remains underinvestigated in HCC. Hereunder, most of the reports on belinostat use in HCC are summarized. A multicenter phase I/II study aimed at determining the drug pharmacokinetic and toxicity profiles constitutes one major such report. The outcomes of the study were favorable in terms of disease stabilization (assessed via histoscores) and high tolerance to the drug, which is reflected in its outspread pharmaceutical window [78]. When combined with the checkpoint inhibitors anti-PD-1 and anti-CTLA-4 antibodies, belinostat potentiated the latter but not the former. The synergy was credited to a drop of regulatory $\mathrm{T}$ cells and a boosted IFN- $\gamma$ production by $\mathrm{T}$ cells in the tumor microenvironment [90]. Withal, $P D-L 1$ inhibition was proposed, given its observed overexpression on antigen-presenting cancer cells and its retarded expression on effector T cells. Boronincorporating prodrugs of belinostat have been propounded for improving its potency against solid tumors [91]. The prodrug form manifested superior bioavailability. However, the efficacy of this form remains to be examined in HCC.

\section{Aliphatic Fatty Acids}

5.1. Valproic Acid (VPA). VPA, a class I and IIa HDACi, has a certain favorability to it, given its reasonable cost and wide safety margin. VPA demonstrated antineoplastic effects in PLC/PRF5 and HepG2 cells [92]. Moreover, VPA was shown to mediate a dissemination of its anticancer activity through its indirect modulation of cell-free DNA. This rather unique study was conducted under the hypothesis that cfDNA can mediate intercellular signaling. The cfDNA derived from VPA-treated cells induced glycolysis in naïve HepG2 cells.
Subsequent analysis of the cfDNA from these cells revealed altered characteristics. As such, it was suggested that VPA treatment can be temporarily propagated across cells via their released cfDNA [93]. VPA rendered Hep3B cells more vulnerable to proton irradiation, protracting the actuated DNA damage, and promoted irradiation-mediated apoptosis [94]. Curiously, VPA increased irradiation-induced reactive oxygen species (ROS) production and silenced nuclear factor erythroid 2-related factor 2 (Nrf2), which is quickly becoming a marker of radioresistance. VPA has been used in combination with doxorubicin [95] and sorafenib [96] and boosted the cytotoxic effects of cytokine-induced killer cells [97]. Recently, VPA was assessed alongside zebularine as to the effect on Suppressor of cytokine signaling 1 (SOCS-1) and Suppressor of cytokine signaling 3 (SOCS-3) expression [98]. Despite both suppressing cellular growth, only VPA demonstrated an apoptotic effect and correlated with an upregulation of SOCS-1 and SOCS-3.

5.2. Sodium Butyrate. Butyrate is among the short chain fatty acids that are produced as a result of the anaerobic fermentation undergone by gut microbiota, and its benefits in restraining tumor growth have been documented. The sodium salt of butyrate has been explored as an epigenetic modulator in various malignancies. However, there remains a need for exploring its utility in HCC. Elevation of ROS and consequent autophagy were noted in Huh7 cells following butyrate treatment. Levels of phosphorylated $A K T$ and $m$ TOR were positively inhibited, which gave to a dependent rise in ATG5, Beclin1, and LC3-II, with subsequent assembly of the autophagosome machinery [99]. Otherwise, as noted with TSA (above), butyrate spurred on the expression of the deubiquitinase CYLD in Huh7 and HepG2 cells (Kotantaki \& Mosialos, 2016).

\section{Noncoding RNAs}

6.1. MicroRNAs. MicroRNAs (miRNAs) are probably the most frequently studied biomolecules in cancer, and for a good reason. Given their integral role in gene expression manipulation, abnormal miRNome lies at the heart of the genetic dysregulation that predisposes to oncogenesis. miRNAs are encoded mostly in intergenic regions of the genome and are transcribed by RNA polymerase II. Following transcription, a primary RNA transcript forms a hairpin loop with terminal single-stranded extensions (Figure 2). Both the $5^{\prime}$ and $3^{\prime}$ extensions are cleaved off by a microprocessing complex made up of DROSHA, a class 2 RNase III and its accessory protein $D G C R 8$, yielding what is referred to as a precursor miRNA (pre-miRNA) (Figure 2). The premiRNA is exported to the cytoplasm shuttled through nuclear pores by the transporter exportin 5 (Figure 2). In the cytoplasm, the pre-miRNA is recognized by the TRPB2bound enzyme Dicer, another RNase III, which clips off the loop, producing a double-stranded miRNA (ds-miRNA or $\mathrm{miR} / \mathrm{miR} *$ duplex) (Figure 2). The Argonaut protein, Ago2, interacts with Dicer to bind the ds-miRNA, unwinding the miRNA duplex, releasing the passenger strand that is degraded and retains the guide strand (Figure 2), which is 


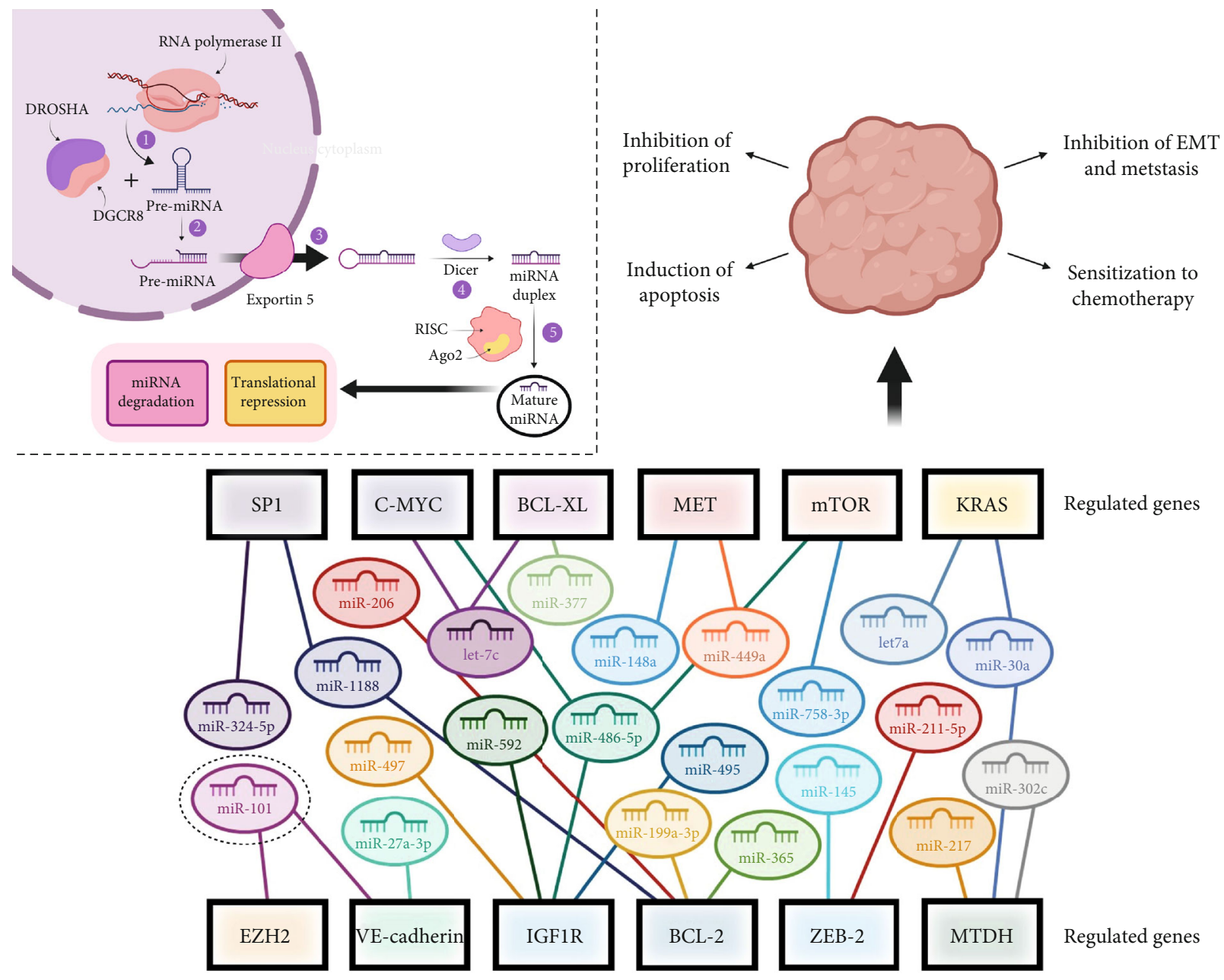

FiguRE 2: A schematic showing a network of several miRNAs with converging regulatory pathways in HCC therapy. The figure shows miRNAs sharing a common target as well as targets regulated by more than one miRNA. The therapeutic effects associated with all of the microRNAs in the illustrated panel correlate with their upregulation, except for miR-101 (marked). "Created with BioRender."

15-25 nucleotides long [100, 101]. Along with Ago2, the guide strand interacts with a group of proteins forming the RNA-induced silencing complex (RISC) which constitutes the active silencing species. Complementarity with the $3^{\prime}$ UTR of target mRNAs determines which are marked for silencing, which is further reinforced by near-perfect complementarity of the mRNA with the miRNA seed sequence. The bound mRNA may be degraded or its translation impeded, turning off the mRNA-encoding gene. Hereinafter, some of the most therapeutically bioactive miRNAs are explored.

6.2. $m i R-126$. $m i R-126$ was shown to target EGFL7 and VEGF in HCC tissues, lowering their expression [102]. Gain of function studies demonstrated that this regulatory mechanism resulted in significant reduction of tumor size and weight as well as a decreased microvascular density of transplanted neoplasms. Other studies further corroborated the antiangiogenic role of $m i R-126 . m i R-126$-transfected HepG2 cells were transplanted in nude mice in parallel with a control group receiving a transplant of nontransfected cells. Postresection analysis revealed lower VEGF expression levels in the miR-126 group compared with controls as well as rela- tively reduced tumor volumes [103]. Du and colleagues [104] reported similar findings for the 3p arm of miR-126. According to the results of their experiments, $m i R-126-3 p$ gain of function inhibited expansion of tumor vasculature and reduced microvascular density and capillary tube formation. Low-density lipoprotein receptor-related protein 6 (LRP6) and phosphoinositide-3-kinase regulatory subunit 2 (PIK3R2) were identified as the direct targets, and their silencing occasioned similar effects to those brought about by overexpression of $m i R-126-3 p$. Beyond its effects on tumor vascularization, $m i R-126$ has manifested antiproliferative and antiapoptotic functionalities. Zhao et al. [105] reported sex-determining region Y-box 2 (SOX2) as a putative target of miR-126. miR-126 mimics correlated with downregulated levels of SOX2 and subsequent cell cycle arrest and apoptosis in HepG2 cells. In addition to the above, miR-126 repressed metastatic capability of HCC. A negative correlation between miR-126 and ADAM metallopeptidase domain 9 (ADAM9) has been established in hepatitis B virus-related HCC [106]. Upregulation of miR-126 attenuated ADAM9 expression and consequently inhibited tumor migration and reduced instances of metastases. Ectopic expression of miR-126 was 
associated with failure of miR-126-trasnfected SMMC-7721 cells to achieve pulmonary colonization in vivo [107]. The miR-126-3p/PIK3R2/LRP6 regulatory loop mentioned above has also been proven to result in the suppression of cellular migration, ECM invasion, and tumor metastasis [104].

6.3. $m i R-148 a$. $m i R-148 a$ has recently been shown to posttranscriptionally regulate the expression of transferrin receptor 1 (TFR1) [108]. Given the negative correlation observed, an increase in $m i R-148 a$ levels is surmised to downregulate TLR1 in HCC, resulting in reduced uptake of transferrinbound iron by the cancer cells, which consequently leads to a drop in cellular iron levels, suppressing proliferation. The closely related $m i R-148 b$ is purported to directly target Rhoassociated protein kinase 1 (ROCK1) to similar antiproliferative effects [109]. Other endeavors indicated that miR-148a mimics might be implicated in the regulation of hepatocytic differentiation via regulating the IKK $\alpha / N U M B / N O T C H$ pathway [110]. Furthermore, miR-148a positively correlated with the expression of $E$-cadherin and downregulated mesenchymal markers, i.e., vimentin, fibronectin, and $\mathrm{N}$-cadherin in hepatoma cells, by binding and inhibiting Met and attenuating its downstream signaling, ultimately resulting in decreased nuclear accumulation of SNAIL [111]. As such, $m i R-148 a$ was effective in discouraging EMT and suppressing pulmonary metastasis. A number of studies sought to examine the role of microRNAs in regulating hepatic stellate cells (HSCs), to outstanding outcomes. miR-148a was shown to target and inhibit growth arrest-specific gene 1 (Gas1) mRNAs, thwarting Hedgehog signaling and preventing biogenesis of autophagosomes, which manifested as enhanced autophagy and apoptosis of HSCs [112]. Interestingly, $m i R$ $148 a$ itself has been shown to be epigenetically regulated in HCC. By virtue of its hypermethylated CpG island, miR$148 a$ is typically silenced in HCC cell lines [113]. Ironically, $D N M T 1$, an established target of $m i R-148 a$, is the DNA methyltransferase that mediates such hypermethylation. DNMT1 is upregulated in HCC, and thus, it downplays its primary regulator by a negative feedback loop. Fortunately, ectopic expression of miR-148a abrogates the inhibitory effects of $D N M T 1$, permitting its regulatory role to take effect.

6.4. miR-199a. miR-199a-3p prompted a diminution of malignant nodular size and numbers in a transgenic mouse model that is prone to developing HCC, coinciding with a downregulation of its putative targets: $p 21$ activated kinase 4 (PAK4) and mTOR, and hence a drop in the levels of FOXM1, replicating effects observed following treatment with sorafenib [114]. Targeted delivery of miR-199a-3p to neoplasms in nude mice displayed similar auspicious outcomes. Mimics of the 3p arm of miR-199a were encapsulated in bionic acid- (BA-) functionalized peptide-based nanoparticles (NPs). Hepatospecific delivery was achieved through the high affinity interaction between BA and the asialoglycoprotein receptors, which are overly expressed in HCC cells. Mirroring $m T O R$ inhibition in vitro, apoptotic and antiproliferative events were noted, following IV administration of the NPs [115]. Preceding in vitro analysis had additionally exposed an upregulation of PUMA secondary to a rise in
ZHX1 levels, concurring with repressed growth. Increased cell death was paralleled by $B c l 2$ tapering off and accretion of cleaved caspase 3 and Bax [116]. Both arms of miR-199a positively modulated E-cadherin through inhibition of its Notch1-mediated suppression [117], which also suggests a role for miR-199a in checking EMT. miR-199a-5p was also shown to restrain metastatic disposition by silencing Snail [118]. The biotherapeutic activity of the $5 p$ arm extends well beyond its regulation of E-cadherin. Upwards of EMT, introducing miR-199a-5p stifled clathrin heavy chain (CTLC) expression arresting cellular growth in vitro and xenograft mice models [119]. Moreover, VEGF-initiated cell proliferation was reportedly halted posttreatment with $m i R-199 a-5 p$, thanks to its modulation of the nitroreductase, NOR1 [120].

6.5. $m i R-503$. Several studies reported antimetastatic effects of $m i R-503$ through dampening the expression of various targets such as WEE1 [121], PRMT1 [122], and ARHGEF19 [123]. Decelerated cellular growth, inducement of apoptosis, and sensitization to chemotherapy were all events associated with $m i R-503$ gain of function and were collateral to its modulation of its determined targets viz. eukaryotic translation initiation factor 4E (EIF4E) [124] and insulin-like growth factor 1 receptor (IGF-1R) [125].

6.6. $m i R-101 . m i R-101$ has been a confirmed tumor suppressor and recurrently reported as a downregulated species in HCC. Marked clampdown of tumor growth has been linked to the modulation of the HGF/c-MET axis by miR-101-3p [126]. $m i R-101$ also attenuated the expression of the zinc-finger protein 217 (ZNF217), a potent effector of malignant immortalization [127]. Further, vasculogenic mimicry, an insidious mechanism of de novo vasculogenesis by which cancer resists angiogenic arrest, was undermined by $m i R$ 101 mimics, which sabotaged TGF- $\beta$ and SDF1 signaling in cancer-associated fibroblasts and impaired VE-cadherin expression [128]. Similar to $m i R-503, m i R-101-3 p$ also targeted WEE1, which was shown to sensitize Huh7 and PLC5 to radiotherapy, an effect that is partially abrogated in HCC by the IncRNA nuclear-enriched abundant transcripts 1 and 2 (NEAT1 and NEAT2) [129]. On top of that, miR-101 subverted the TGF- $\beta 1$-instigated build-up of extracellular matrix (ECM), reversing hepatic fibrosis, and blunted the levels of phosphorylated PI3K, $m T O R$, and Akt [130]. As with other epigenetic modulators, $m i R-101$ has been tried as a part of several combinatorial regimens. Synergy was reported with liposomal doxorubicin [131] and the lncRNA LINC00052, which promoted the expression of the $3 p$ arm of miR-101 that restricted the expression of SRY-related HMG-box gene 9 (SOX9) [132].

As is evident in Figure 2 and Table 4, different miRNAs have common targets and inevitably a single target can be regulated by more than one miRNA, which creates an elaborate regulatory network and sometimes complicate the utilization of miRNAs for diagnostic and therapeutic purposes.

6.7. Long Noncoding RNAs. Another major class of nonproteincoding RNAs that is central to HCC and which is gaining significant attention as of late is long noncoding RNAs 


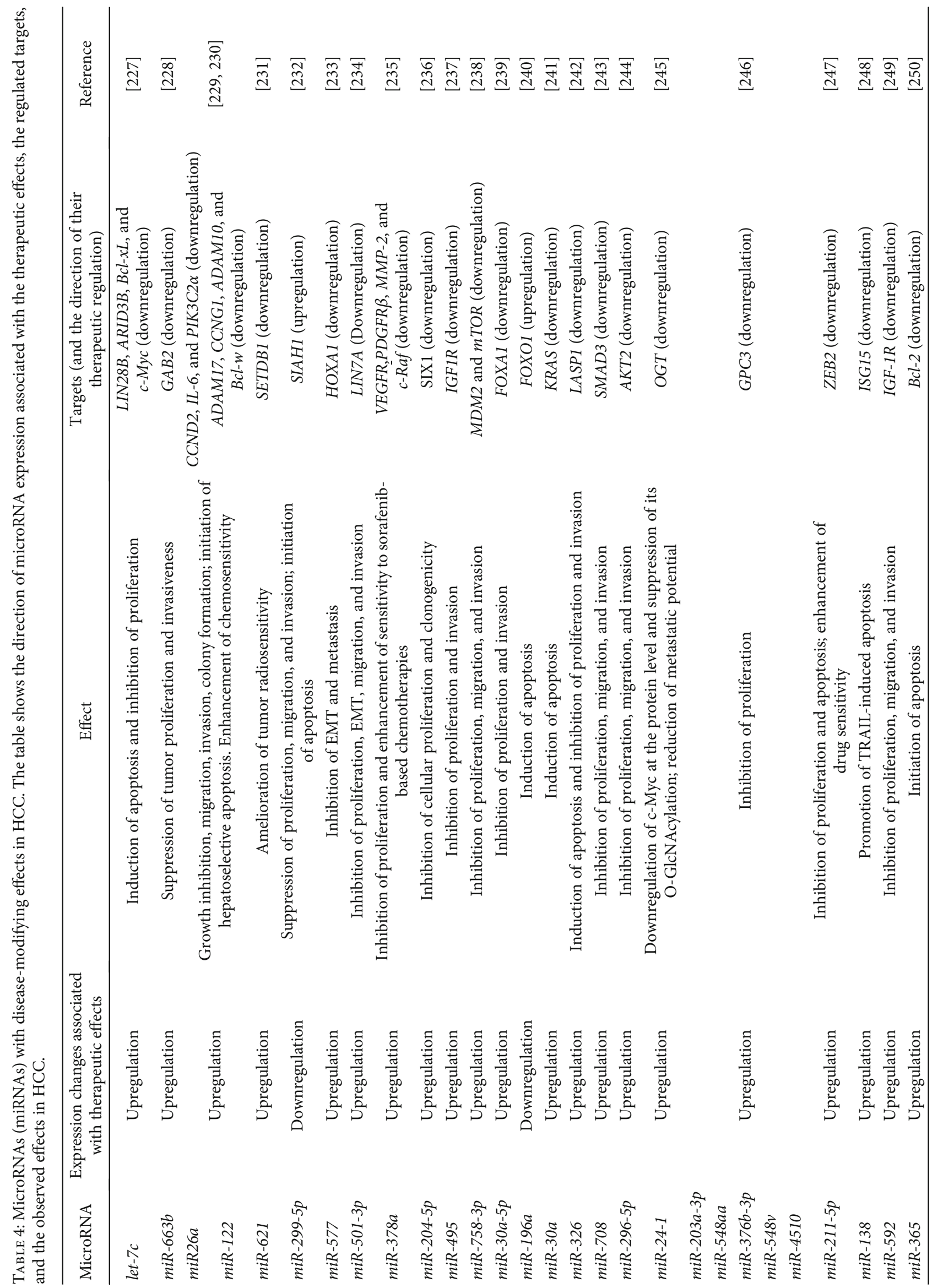




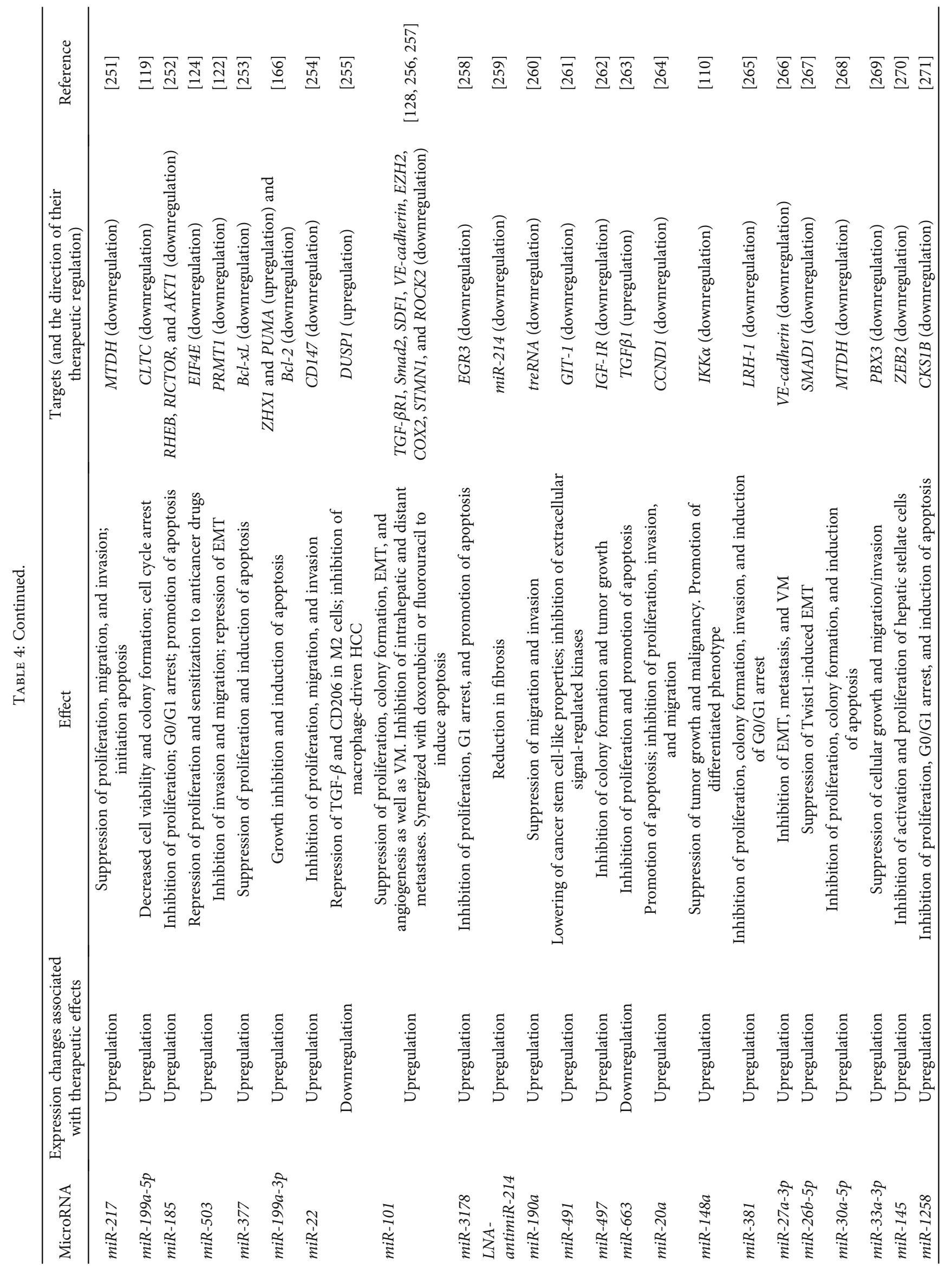




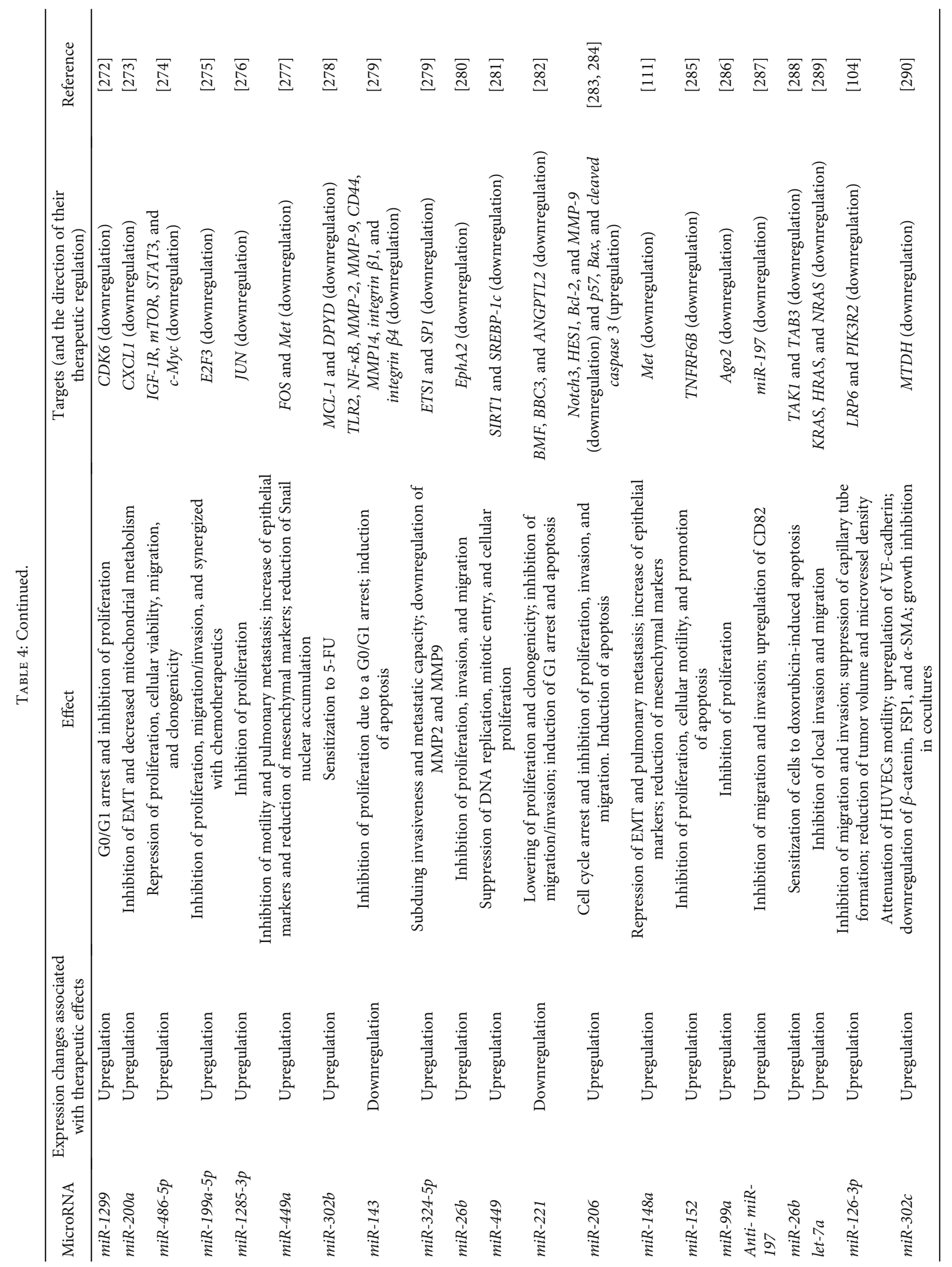




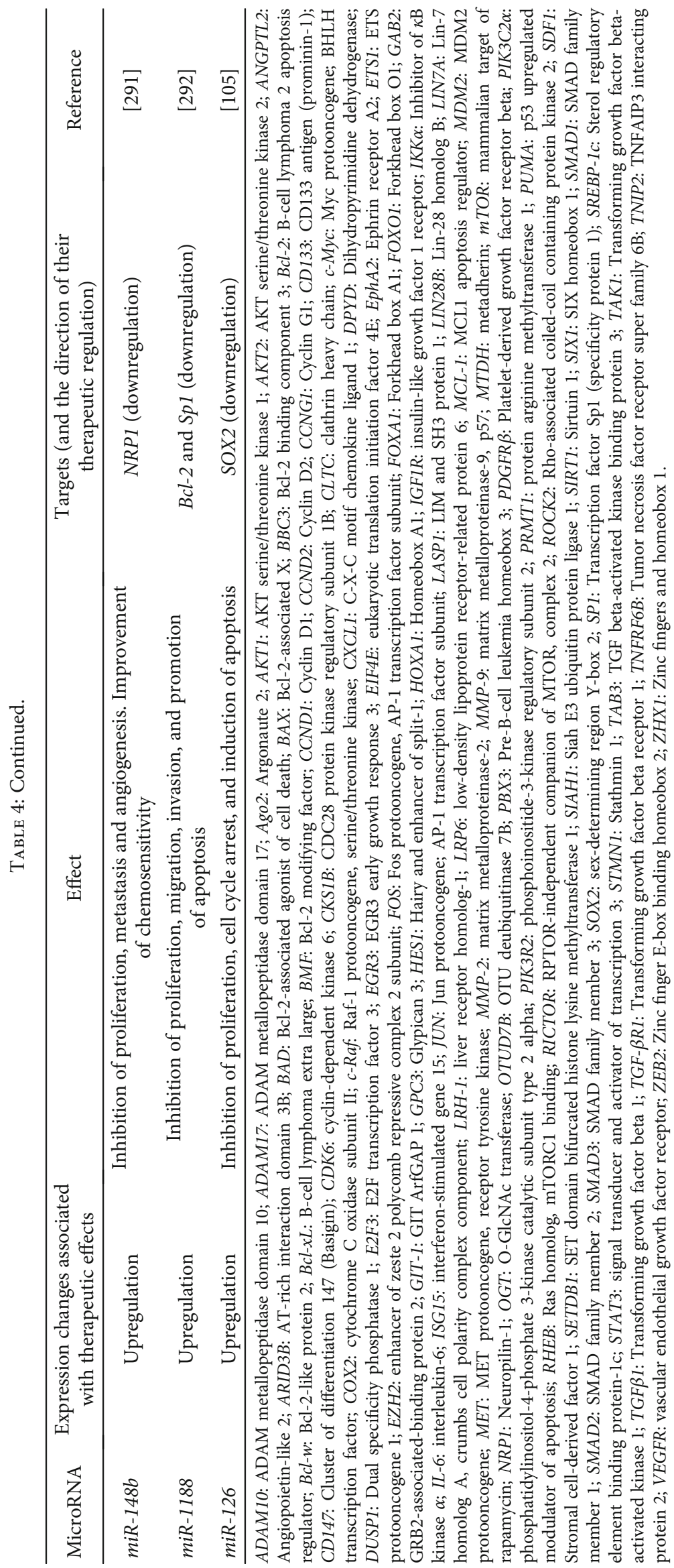


(lncRNAs). lncRNAs are a bit longer than miRNAs with a transcript length of more than 200 nucleotides [133]. lncRNAs have been extensively researched for their role in HCC pathogenesis and their therapeutic potential. As will be exposited shortly, a number of lncRNAs function by what is known as miRNA sponges, which basically involves buffering the action of miRNAs on their target mRNAs.

Given the comprehensive nature of this review, only some of the most recent reports involving lncRNA in HCC are discussed below. However, detailed information about earlier reports can be found in the following reviews: [134-136]. Additionally, the following bibliographic data [134-214] afford an extensive exposition of the most recent HCC IncRNA-oriented work. Beside the compendious runthrough below, Table 5 affords an encyclopedic overview of the lncRNAs studied in these resources which were not discussed in the text for practical reasons.

6.8. GAS8-AS1. It was recently reported that both the GAS8 gene and its resident lncRNA, GAS8-AS1, act as tumor suppressors and manifest a significantly low expression in HCC tissues, which correlated with poor prognosis [157]. GAS8-AS1 was curiously found to mediate the transcription of GAS8. It was essential in maintaining chromatin in an uncondensed state by recruiting the $\mathrm{H} 3 \mathrm{~K} 4$ methyltransferase $M L L 1$ and its accessory protein $W D-40$ repeat protein 5 (WDR5). This leads to the potentiation of RNA polymerase II and enhanced transcription of GAS8. The above molecular events suppressed oncogenesis and impeded HCC development.

6.9. FENDRR. FOXF1 adjacent noncoding developmental regulatory RNA (FENDRR), another IncRNA that was found to be downregulated in HCC, was recently advocated as a potential therapeutic approach to arrest HCC progression and discourage metastasis. Ectopic expression of FENDRR was reported to check malignant growths in vitro and in vivo, as well as repressing HCC migration and invasion. This was purported to occur via epigenetic regulation of glypican-3 (GPC3). Through interacting with the GPC3 promoter and subsequently leading to its methylation, FENDRR functions to silence GPC3, counteracting the latter's oncogenic effects [168].

6.10. CASC2c. Cancer susceptibility candidate $2 c$ (CASC2c) is one of three lncRNA transcripts produced by the alternative splicing of cancer susceptibility 2 (CASC2). Inherently silenced in HCC, the overexpression of CASC2c resulted in the suppression of proliferation of HCC cells, while inducing apoptosis. These effects coincided with lowered phosphorylated extracellular signal-regulated kinase $1 / 2$ ( $p$-ERK1/2) and $\beta$-catenin levels [201].

6.11. $m i R 503 H G$. $m i R 503 H G$, the host gene of $m i R-503$ (see above), has been found to be significantly downregulated in HCC [141]. This silencing was closely related to survival rates and duration until tumor recurrence and is thus conjectured to be a prognostic biomarker. The gain of function abrogated the invasion and metastasis of HCC cells. miR503HG was also found to promote the degradation of the heterogeneous nuclear ribonucleoprotein A2/B1 (HNRNPA2B1) by ubiquitination and subsequent proteasomal degradation, which consequently led to the destabilization of $p 52$ and $p 65$ transcripts and ultimately suppressed $N F-\kappa B$ signaling in HCC. Given their innate interplay and their common effect on HCC cells, miR503HG and its resident microRNA (miR-503) could cooperatively function to stymie migration of HCC cells.

6.12. LINC00467. LINC00467, another IncRNA that was found to be downregulated in HCC, has been studied as a potential therapeutic target thanks to its role as an antagomir for miR-9-5a, which targets peroxisome proliferator-activated receptor alpha (PPARA) for silencing [140]. LINC00467 ectopically expressed in HCC cells conduced to antiproliferative effects and, like miR503HG, checked migration and invasion. The authors propose a pivotal implication of the LINC00467/miR-9-5p/PPARA loop in the initiation and progression of HCC.

6.13. Linc-GALH and UC001kfo. Contrary to the abovementioned lncRNAs, which are downregulated in HCC and which are considered tumor suppressors, other lncRNAs are oncogenic, with anomalously high expression in HCC. Linc-GALH and UC001kfo were recently reported to be upregulated in HCC. Linc-GALH was surmised to regulate methylation of Gankyrin and hence its expression [190]. Mechanistically, this was proposed to occur via deubiquitinating DNMT1. This promoted migration and invasion in HCC cells and was rescinded in silencing experiments. Increased expression of UC001kfo correlated with tumoral macrovascular invasion (MVI) and TNM staging of HCC, with higher levels predisposing to poorer prognoses [179]. UC001fko boosted tumor proliferation and EMT, presumably through targeting alpha-smooth muscle actin ( $\alpha$-SMA). The authors indicate the potential of UC001kfo to serve as a prognostic marker as well as a target for therapy.

6.14. LINC00346. LINC00346 was shown to be aberrantly upregulated in HCC [139]. LINC00346 enhanced the expression of WD Repeat Domain 18 (WDR18) by virtue of competitively binding to $m i R-542-3 p$, a downregulated tumor suppressor in HCC cells. This sponging effect leads to the activation of the Wnt/ $\beta$-catenin pathway. As such, LINC00346 could be a viable target in HCC therapy, where its inhibition is presumed to unmask the anticancer effects of $m i R-542-p$.

6.15. LINC00978. Both tumor tissues and serum samples from HCC patients manifested an exaggerated expression of LINC00978 [69]. Serum levels of this lncRNA could even distinguish between HCC patients and patients with hepatitis or cirrhosis. LINC00978 was reported to promote cellular proliferation, migration, and invasion, wherein its knockdown arrested the cell cycle and encouraged apoptosis. The authors unveiled the mechanistic basis of such effects to involve binding of LINC00978 to EZH2, leading to its buildup at the promoter regions of E-cadherin and $p 21$ genes, which leads to these genes becoming silenced subsequent of EZH2-mediated $\mathrm{H} 27 \mathrm{~K} 3$ trimethylation. The validity of this regulatory circuit was confirmed by the abrogation of 


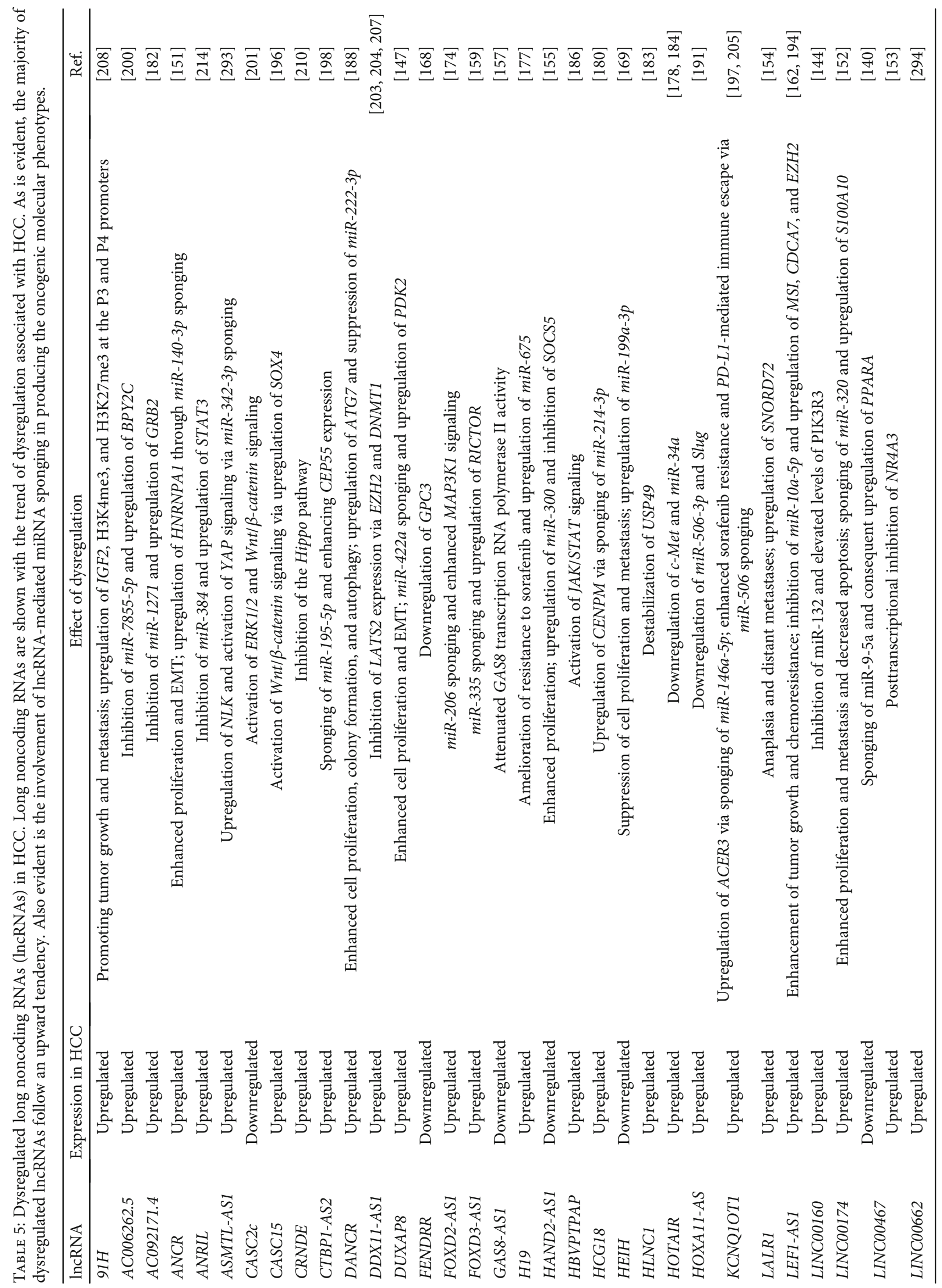




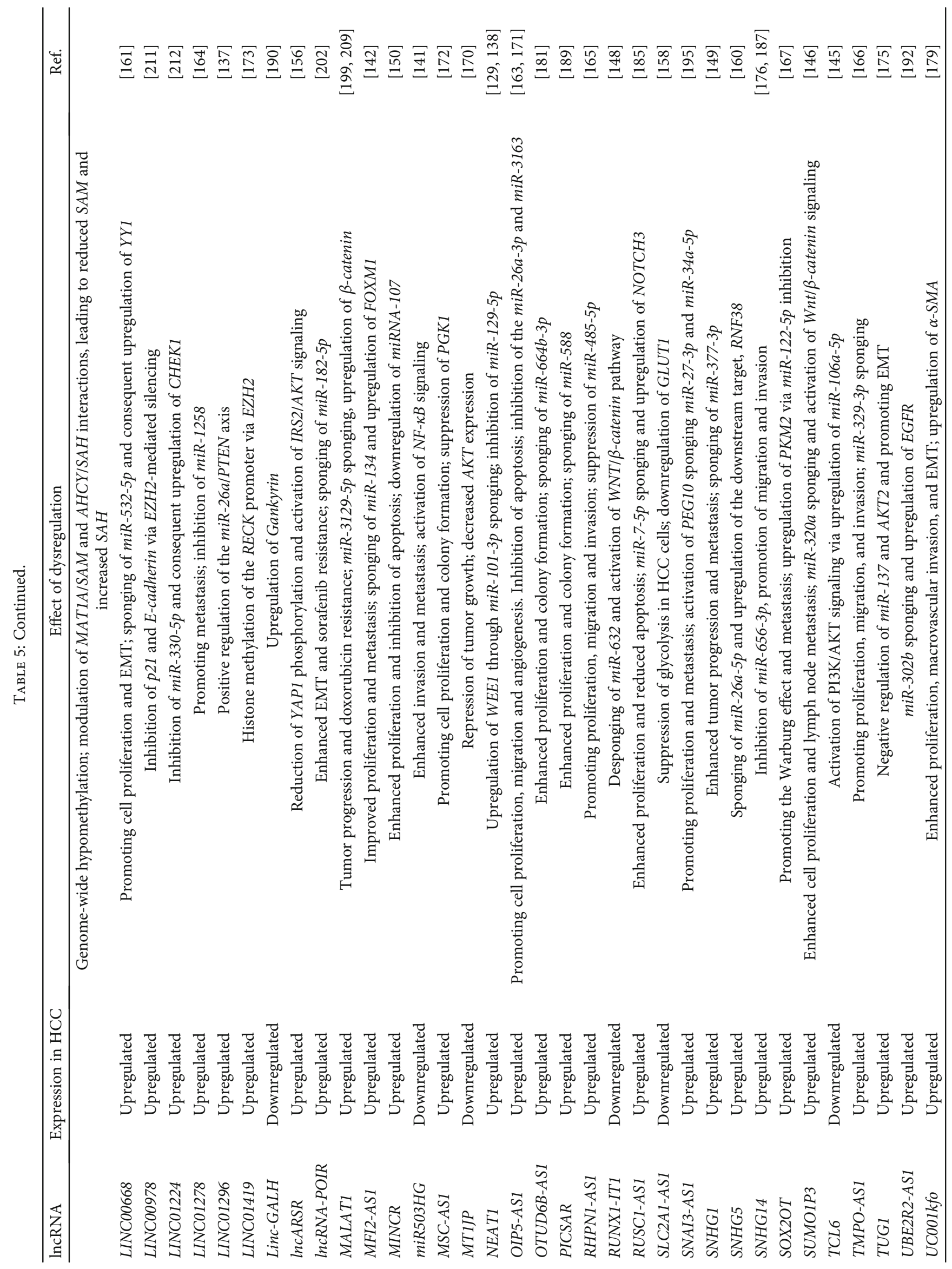




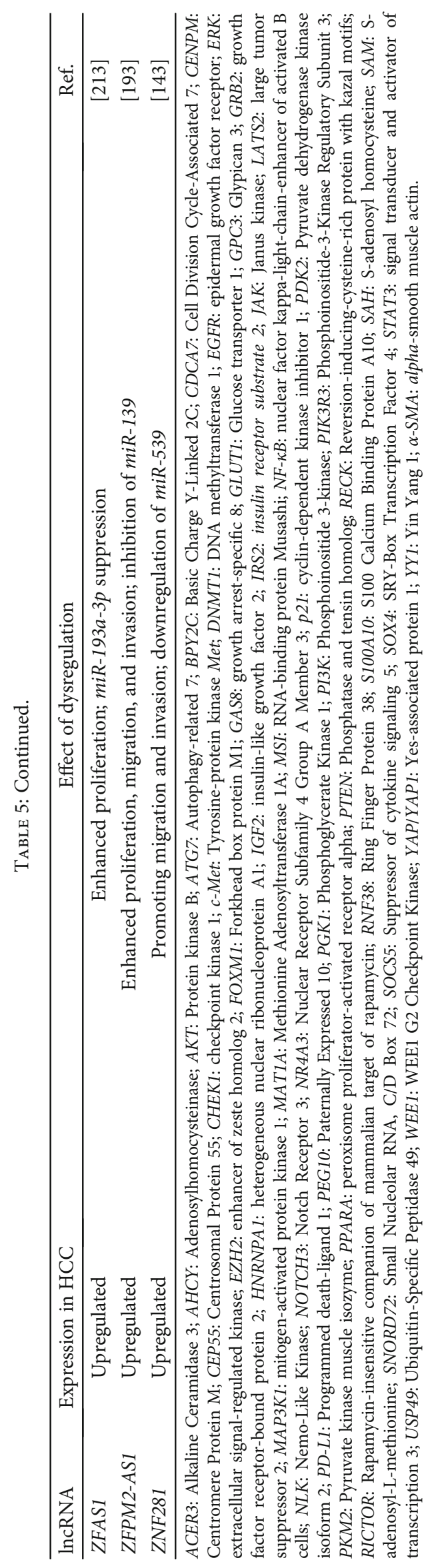


LINC00978 knockdown's inhibitory effects in E-cadherin and p21 knockdowns.

6.16. NEAT1. Nuclear-enriched abundant transcript 1 (NEAT1) is another IncRNA that is upregulated in HCC [138]. Silencing of NEAT1 compromised cell viability and was shown to be proapoptotic in HepG2 and Huh7 cells. Again, as with other lncRNA/miRNA-negative correlations, NEAT1 exhibited an opposite trend of expression to $m i R-$ 129-5p in HCC. Ectopic expression of NEAT1 suppressed miR-129-5p via modulating the valosin-containing protein $(V C P) / I \kappa B$ axis to the overall result of encouraging cellular proliferation.

6.17. ANRIL, LINC01296, and LINC01224. Similarly, antisense noncoding RNA in the INK4 locus (ANRIL), LINC01296, and LINC01224 were all overexpressed in HCC and mediated their oncogenic effects through inhibition of microRNA signaling axes. ANRIL's prooncogenic effects were found to rely on its suppression of $m i R-384$, which targets signal transducer and activator of transcription 3 (STAT3) [214]. These correlations were observed both in vitro and in vivo. LINC01296 regulated the miR-26a/PTEN axis, resulting in tumor progression also in vitro and in vivo [137]. Similarly, an upswing of LINC01224 in HCC was correlated with a silenced miR-330-5p and a consequent upregulation of its target, checkpoint kinase 1 (CHEK1) [212]. LINC01224 knockdowns exhibited a concurrent downregulation of $C H E K 1$, owing to its binding to and inhibition of $m i R-330-5 p$, leading to tumor regression.

6.18. ZFAS1. HCC tissues exhibited an increased level of ZFAS1, compared to neighboring normal tissues [69]. The proliferative capacity of the tumor was substantially compromised subsequent of ZFAS1 silencing, and its overexpression had a gainful effect on tumor growth. The authors report that the tumor suppressor miRNA, miR-193a-3p, was elevated in ZFAS1 knockdowns which, confirmed by luciferase reporter assay and correlation analysis, suggested that the prooncogenic role of ZFAS1 relied on the suppression of miR$193 a-3 p$.

6.19. CRNDE. The colorectal neoplasia differentially expressed $(C R N D E)$ lncRNA has recently been proven to be yet another prooncogenic lncRNA in HCC [210]. Its overexpression was associated with an enhanced proliferative and migratory competence of HCC cells, not to mention an ameliorated resistance to chemotherapy. CRNDE was determined to inhibit the Hippo pathway and encourage the EZH2-, SUV39H1-, and SUZ12-mediated inhibition of tumor suppressor genes viz. large tumor suppressor 2 (LATS2) and CUGBP Elav-like family member 2 (CELF2).

6.20. MALAT1. MALAT1 is a notoriously tumorigenic lncRNA implicated in many cancers. Recently, Chang et al. [209] proposed exploiting a MALAT1/Wnt regulatory loop for therapeutic purposes in HCC. They reported that MALAT1 knockdowns evidenced a suppression of canonical Wnt signaling and impaired tumorsphere formation, which was coincident with a decline in CD90+ and CD133+ cells, which consolidated the hypothesis that MALAT1 plays a vital role in promoting stemness in HCC cells.

\section{Future Perspective}

Despite the thorough study of epigenetic modulators, their extension to the clinical setting stands far from realizable. Further research mindful of the efficacy versus long-term toxicity/of these alternative strategies should be advocated. Studies looking into the pharmacokinetics of these agents as well as others seeking efficient targeted delivery with minimal systemic side effects are warranted. Addressing the adaptability of these modes of treatment to the clinic can bring us a long way, especially with the dosing curtailment of the highly toxic agents afforded by the concomitant use of the suggested alternatives, which, in some instances, may completely replace current debilitating treatments. As was mentioned, various exploratory clinical studies were carried out, but these need to be seen through to subsequent trial phases and on larger populations. Fortunately, the possible risk posed by a preponderance of these modulators is not significant to impede but should embolden such undertakings.

In addition to the clinical application, endeavors oriented to further our understanding of the elaborate epigenome and its regulation remain imperative. New epigenetic mechanisms are still being discovered contemporarily and progress in the field could do with pursuing modulators of these and assessing their benefits over the already defined ones. For example, decreased crotonylation of histone lysines has been recently incriminated in the progression of HCC [215]. This discovery should prompt several spin-offs in which the enhancers of crotonylation are suggested and assessed for therapeutic utility. Several defined modulatory agents such as histone demethylases (specifically Jumonji lysine demethylases) and helicases (HELLS) [216] among others also remain underresearched in HCC and should thus constitute a future research direction in HCC therapeutics.

\section{Conclusion}

The modulation of the altered epigenome in HCC is a promising therapeutic strategy. Verified potency and tenability to formulation demands for maximal systemic effects render many of the hereinabove nominated agents an intriguing recourse that could be subsequently implemented in clinical settings as a standalone curative or a potentiating adjuvant. It would also remain of equal importance to examine if these modulators can act in parallel to attenuate metastasis. More importantly, validating the use of these modulators in the treatment of HCC with different etiologies will aid in paving the road for personalized medicine together with the advancements in the pharmacogenomics/pharmacogenetics field. This holistic approach is forecasted to lower the success barrier, at least in part, in the treatment of HCC.

\section{Conflicts of Interest}

The authors declare that they have no conflicts of interest. 


\section{References}

[1] M. Sayiner, P. Golabi, and Z. M. Younossi, "Disease burden of hepatocellular carcinoma: a global perspective," Digestive Diseases and Sciences, vol. 64, no. 4, pp. 910-917, 2019.

[2] A. K. Singh, R. Kumar, and A. K. Pandey, "Hepatocellular carcinoma: causes, mechanism of progression and biomarkers," Current chemical genomics and translational medicine, vol. 12, no. 1, pp. 9-26, 2018.

[3] L. Ma, M.-S. Chua, O. Andrisani, and S. So, "Epigenetics in hepatocellular carcinoma: an update and future therapy perspectives," World Journal of Gastroenterology, vol. 20, no. 2, pp. 333-345, 2014.

[4] J. I. Martín-Subero and M. Esteller, "Epigenetic mechanisms in cancer development," in The Molecular Basis of Human Cancer, pp. 263-275, Springer, New York, 2016.

[5] M. A. Dawson and T. Kouzarides, "Cancer epigenetics: from mechanism to therapy," Cell, vol. 150, no. 1, pp. 12-27, 2012.

[6] Y.-F. Zheng, X. Lu, X.-Y. Zhang, and B.-G. Guan, "The landscape of DNA methylation in hepatocellular carcinoma," Journal of Cellular Physiology, vol. 234, no. 3, pp. 26312638, 2018.

[7] T. H. Bestor, "The DNA methyltransferases of mammals," Human Molecular Genetics, vol. 9, no. 16, pp. 2395-2402, 2000.

[8] K. D. Robertson, "DNA methylation and human disease," Nature Reviews Genetics, vol. 6, no. 8, pp. 597-610, 2005.

[9] T. S. Han, H. S. Ban, K. Hur, and H. S. Cho, "The epigenetic regulation of HCC metastasis," International Journal of Molecular Sciences, vol. 19, no. 12, p. 3978, 2018.

[10] G. Egger, S. Jeong, S. G. Escobar et al., "Identification of DNMT1 (DNA methyltransferase 1) hypomorphs in somatic knockouts suggests an essential role for DNMT1 in cell survival," Proceedings of the National Academy of Sciences of the United States of America, vol. 103, no. 38, pp. 1408014085, 2006.

[11] D. Subramaniam, R. Thombre, A. Dhar, and S. Anant, "DNA methyltransferases: a novel target for prevention and therapy," Frontiers in Oncology, vol. 4, 2014.

[12] K. D. Robertson, E. Uzvolgyi, G. Liang et al., "The human DNA methyltransferases (DNMTs) 1, 3a and 3b: coordinate mRNA expression in normal tissues and overexpression in tumors," Nucleic Acids Research, vol. 27, no. 11, pp. 22912298, 1999.

[13] K. Revill, T. Wang, A. Lachenmayer et al., "Genome-wide methylation analysis and epigenetic unmasking identify tumor suppressor genes in hepatocellular carcinoma," Gastroenterology, vol. 145, no. 6, pp. 1424-1435.e25, 2013.

[14] I. Martinez-Quetglas, R. Pinyol, D. Dauch et al., "IGF2 is up-regulated by epigenetic mechanisms in hepatocellular carcinomas and is an actionable oncogene product in experimental models," Gastroenterology, vol. 151, no. 6, pp. 1192-1205, 2016.

[15] F. Xu, C. H. Li, C. H. Wong et al., "Genome-wide screening and functional analysis identifies tumor suppressor long non-coding RNAs epigenetically silenced in hepatocellular carcinoma," Cancer Research, vol. 79, no. 7, pp. 1305-1317, 2019.

[16] D. P. F. Tsang, W. K. K. Wu, W. Kang et al., "Yin Yang 1mediated epigenetic silencing of tumour-suppressive microRNAs activates nuclear factor $-\kappa \mathrm{B}$ in hepatocellular carci- noma," The Journal of Pathology, vol. 238, no. 5, pp. 651664, 2016.

[17] C.-M. Wong, L. Wei, C.-T. Law et al., "Up-regulation of histone methyltransferase SETDB1 by multiple mechanisms in hepatocellular carcinoma promotes cancer metastasis," Hepatology, vol. 63, no. 2, pp. 474-487, 2016.

[18] M. Okano, S. Takebayashi, K. Okumura, and E. Li, “Assignment of cytosine-5 DNA methyltransferases $<\mathrm{i}>$ Dnmt3a $</ \mathrm{i}>$ and $<\mathrm{i}>\mathrm{Dnmt} 3 \mathrm{~b}</ \mathrm{i}>$ to mouse chromosome bands $12 \mathrm{~A} 2-\mathrm{A} 3$ and $2 \mathrm{H} 1$ by in situ hybridization," Cytogenetic and Genome Research, vol. 86, no. 3-4, pp. 333-334, 1999.

[19] G. L. Xu, T. H. Bestor, D. Bourc'his et al., "Chromosome instability and immunodeficiency syndrome caused by mutations in a DNA methyltransferase gene," Nature, vol. 402, no. 6758 , pp. $187-191,1999$.

[20] L. Di Croce, V. A. Raker, M. Corsaro et al., "Methyltransferase recruitment and DNA hypermethylation of target promoters by an oncogenic transcription factor," Science, vol. 295, no. 5557, pp. 1079-1082, 2002.

[21] B.-K. Oh, H. Kim, H.-J. Park et al., "DNA methyltransferase expression and DNA methylation in human hepatocellular carcinoma and their clinicopathological correlation," International Journal of Molecular Medicine, vol. 20, no. 1, pp. 65-73, 2007.

[22] H. Li, T. Rauch, Z. X. Chen, P. E. Szabó, A. D. Riggs, and G. P. Pfeifer, "The histone methyltransferase SETDB1 and the DNA methyltransferase DNMT3A interact directly and localize to promoters silenced in cancer cells," The Journal of Biological Chemistry, vol. 281, no. 28, pp. 19489-19500, 2006.

[23] M. H. Lee, H. Na, T. Y. Na, Y. K. Shin, J. K. Seong, and M. O. Lee, "Epigenetic control of metastasis-associated protein 1 gene expression by hepatitis $\mathrm{B}$ virus $\mathrm{X}$ protein during hepatocarcinogenesis," Oncogene, vol. 1, no. 9, 2012.

[24] J. Yu, X. Yuan, L. Sjöholm et al., “Telomerase reverse transcriptase regulates DNMT3B expression/aberrant DNA methylation phenotype and AKT activation in hepatocellular carcinoma," Cancer Letters, vol. 434, pp. 33-41, 2018.

[25] H. Fan, L. Chen, F. Zhang et al., "MTSS1, a novel target of DNA methyltransferase $3 \mathrm{~B}$, functions as a tumor suppressor in hepatocellular carcinoma," Oncogene, vol. 31, no. 18, pp. 2298-2308, 2012.

[26] Z. Zhao, Q. Wu, J. Cheng, X. Qiu, J. Zhang, and H. Fan, "Depletion of DNMT3A suppressed cell proliferation and restored PTEN in hepatocellular carcinoma cell," Journal of Biomedicine \& Biotechnology, vol. 2010, 10 pages, 2010.

[27] G. Szparecki, T. Ilczuk, D. Wolosz, W. Otto, and B. Gornicka, "The expression of DNA methyltransferase DNMT3a in classical and fibrolamellar hepatocellular carcinoma," Journal of Clinical and Experimental Pathology, vol. 6, no. 3, 2016.

[28] M. S. Kareta, Z. M. Botello, J. J. Ennis, C. Chou, and F. Chédin, "Reconstitution and mechanism of the stimulation of de novo methylation by human DNMT3L," The Journal of Biological Chemistry, vol. 281, no. 36, pp. 25893-25902, 2006.

[29] L. Gailhouste, L. C. Liew, K. Yasukawa et al., "Differentiation therapy by epigenetic reconditioning exerts antitumor effects on liver cancer cells," Molecular Therapy, vol. 26, no. 7, pp. 1840-1854, 2018.

[30] S. O. Sajadian, S. Ehnert, H. Vakilian et al., "Induction of active demethylation and $5 \mathrm{hmC}$ formation by 5 -azacytidine is TET2 dependent and suggests new treatment strategies 
against hepatocellular carcinoma," Clinical Epigenetics, vol. 7, no. 1, p. 98, 2015.

[31] Y. K. Hong, Y. Li, H. Pandit et al., "Epigenetic modulation enhances immunotherapy for hepatocellular carcinoma," Cellular Immunology, vol. 336, pp. 66-74, 2019.

[32] S. O. Sajadian, C. Tripura, F. S. Samani et al., "Vitamin C enhances epigenetic modifications induced by 5 -azacytidine and cell cycle arrest in the hepatocellular carcinoma cell lines HLE and Huh7," Clinical Epigenetics, vol. 8, no. 1, p. 46, 2016.

[33] A. Ilyas, Z. Hashim, and S. Zarina, "Effects of $5^{\prime}$-azacytidine and alendronate on a hepatocellular carcinoma cell line: a proteomics perspective," Molecular and Cellular Biochemistry, vol. 405, no. 1-2, pp. 53-61, 2015.

[34] M. Sanaei, F. Kavoosi, and Z. Esmi, “The effect of 5-aza-2' -deoxycytidine in combination to and in comparison with vorinostat on DNA methyltransferases, histone deacetylase 1 , glutathione S-transferase 1 and suppressor of cytokine signaling 1 genes expression, cell growth inhibition and apoptotic induction in hepatocellular LCL-PI 11 cell line," International Journal of Hematology-Oncology and Stem Cell Research, vol. 14, no. 1, pp. 45-55, 2020.

[35] S.-I. Suh, H.-Y. Pyun, J.-W. Cho et al., "5-Aza-2' -deoxycytidine leads to down-regulation of aberrant p16INK4A RNA transcripts and restores the functional retinoblastoma protein pathway in hepatocellular carcinoma cell lines," Cancer Letters, vol. 160, no. 1, pp. 81-88, 2000.

[36] B. Lin, X. Zhou, S. Lin et al., "Epigenetic silencing of PRSS3 provides growth and metastasis advantage for human hepatocellular carcinoma," Journal of Molecular Medicine, vol. 95, no. 11, pp. 1237-1249, 2017.

[37] Q. Mei, M. Chen, X. Lu et al., “An open-label, single-arm, phase I/II study of lower-dose decitabine based therapy in patients with advanced hepatocellular carcinoma," Oncotarget, vol. 6, no. 18, pp. 16698-16711, 2015.

[38] S. Jueliger, J. Lyons, S. Cannito et al., "Efficacy and epigenetic interactions of novel DNA hypomethylating agent guadecitabine (SGI-110) in preclinical models of hepatocellular carcinoma," Epigenetics, vol. 11, no. 10, pp. 709-720, 2016.

[39] Y. Kuang, A. El-Khoueiry, P. Taverna, M. Ljungman, and N. Neamati, "Guadecitabine (SGI-110) priming sensitizes hepatocellular carcinoma cells to oxaliplatin," Molecular Oncology, vol. 9, no. 9, pp. 1799-1814, 2015.

[40] A. Gnyszka, Z. Jastrzebski, and S. Flis, "DNA methyltransferase inhibitors and their emerging role in epigenetic therapy of cancer," Anticancer Research, vol. 33, no. 8, pp. 2989-2996, 2013.

[41] C. Raggi, V. M. Factor, D. Seo et al., "Epigenetic reprogramming modulates malignant properties of human liver cancer," Hepatology, vol. 59, no. 6, pp. 2251-2262, 2014.

[42] K. Nakamura, K. Aizawa, K. Nakabayashi et al., "DNA methyltransferase inhibitor zebularine inhibits human hepatic carcinoma cells proliferation and induces apoptosis," PLoS One, vol. 8, no. 1, article e54036, 2013.

[43] M. Sanaei and F. Kavoosi, "Effect of zebularine in comparison to and in combination with trichostatin a on CIP/KIP family (p21Cip1/Waf1/Sdi1, p27Kip1, and p57Kip2), DNMTs (DNMT1, DNMT3a, and DNMT3b), class I HDACs (HDACs 1, 2, 3) and class II HDACs (HDACs 4, 5, 6) gene expression, cell growth inhibition and apoptosis induction in colon cancer LS $174 \mathrm{~T}$ cell line," Asian Pacific Journal of Cancer Prevention, vol. 21, no. 7, pp. 2131-2139, 2020.
[44] S. R. Lepri, D. Sartori, S. C. Semprebon, A. Baranoski, G. C. Coatti, and M. S. Mantovani, "Genistein affects expression of cytochrome P450 (CYP450) genes in hepatocellular carcinoma (HEPG2/C3A) cell line," Drug Metabolism Letters, vol. 12, no. 2, pp. 138-144, 2018.

[45] S. R. Lee, S. W. Kwon, Y. H. Lee et al., "Dietary intake of genistein suppresses hepatocellular carcinoma through AMPK-mediated apoptosis and anti-inflammation," BMC Cancer, vol. 19, no. 1, p. 6, 2019.

[46] M. Sanaei, F. Kavoosi, A. Roustazadeh, and F. Golestan, "Effect of genistein in comparison with trichostatin A on reactivation of DNMTs genes in hepatocellular carcinoma," Journal of Clinical and Translational Hepatology, vol. 6, no. 2, pp. 141-146, 2018.

[47] M. Sanaei, F. Kavoosi, and H. Salehi, "Genistein and trichostatin A induction of estrogen receptor alpha gene expression, apoptosis and cell growth inhibition in hepatocellular carcinoma HepG 2 cells," Asian Pacific Journal of Cancer Prevention, vol. 18, no. 12, pp. 3445-3450, 2017.

[48] S. Bimonte, V. Albino, M. Piccirillo et al., "Epigallocatechin3-gallate in the prevention and treatment of hepatocellular carcinoma: experimental findings and translational perspectives," Drug Design, Development and Therapy, vol. Volume 13, pp. 611-621, 2019.

[49] J. L. Won, J. Y. Shim, and B. T. Zhu, "Mechanisms for the inhibition of DNA methyltransferases by tea catechins and bioflavonoids," Molecular Pharmacology, vol. 68, no. 4, pp. 1018-1030, 2005.

[50] V. S. Thakur, G. Deb, M. A. Babcook, and S. Gupta, "Plant phytochemicals as epigenetic modulators: role in cancer chemoprevention," The AAPS Journal, vol. 16, no. 1, pp. 151$163,2014$.

[51] S. Li, L. Wu, J. Feng et al., "In vitro and in vivo study of epigallocatechin-3-gallate-induced apoptosis in aerobic glycolytic hepatocellular carcinoma cells involving inhibition of phosphofructokinase activity," Scientific Reports, vol. 6, 2016.

[52] D. Sabry, O. O. Abdelaleem, A. M. el Amin Ali et al., "Anti-proliferative and anti-apoptotic potential effects of epigallocatechin-3-gallate and/or metformin on hepatocellular carcinoma cells: in vitro study," Molecular Biology Reports, vol. 46, no. 2, pp. 2039-2047, 2019.

[53] Y. Wen, R.-Q. Zhao, Y.-K. Zhang et al., "Effect of Y6, an epigallocatechin gallate derivative, on reversing doxorubicin drug resistance in human hepatocellular carcinoma cells," Oncotarget, vol. 8, no. 18, pp. 29760-29770, 2017.

[54] C. L. Peterson and M. A. Laniel, "Histones and histone modifications," Current Biology, vol. 14, no. 14, pp. R546-R551, 2004.

[55] T. B. Toh, J. J. Lim, and E. K.-H. Chow, "Epigenetics of hepatocellular carcinoma," Clinical and Translational Medicine, vol. 8, no. 1, p. 13, 2019.

[56] B. Wahid, A. Ali, S. Rafique, and M. Idrees, "New insights into the epigenetics of hepatocellular carcinoma," BioMed Research International, vol. 2017, 16 pages, 2017.

[57] C. Sawan and Z. Herceg, "Histone modifications and cancer," Advances in Genetics, vol. 70, pp. 57-85, 2010.

[58] Y. Chervona and M. Costa, "Histone modifications and cancer: biomarkers of prognosis?," American Journal of Cancer Research, vol. 2, no. 5, pp. 589-597, 2012.

[59] W. Fu, L. Gao, C. Huang et al., "Mechanisms and importance of histone modification enzymes in targeted therapy for 
hepatobiliary cancers," Discovery medicine, vol. 28, no. 151, pp. 17-28, 2019.

[60] S. Y. Roth, J. M. Denu, and C. D. Allis, "Histone acetyltransferases," Annual Review of Biochemistry, vol. 70, no. 1, pp. 81-120, 2001.

[61] S. Ropero and M. Esteller, "The role of histone deacetylases (HDACs) in human cancer," Molecular Oncology, vol. 1, no. 1, pp. 19-25, 2007.

[62] M. Haberland, R. L. Montgomery, and E. N. Olson, "The many roles of histone deacetylases in development and physiology: implications for disease and therapy," Nature Reviews Genetics, vol. 10, no. 1, pp. 32-42, 2009.

[63] K. J. Falkenberg and R. W. Johnstone, "Histone deacetylases and their inhibitors in cancer, neurological diseases and immune disorders," Nature Reviews Drug Discovery, vol. 13, no. 9, pp. 673-691, 2014.

[64] E. Ceccacci and S. Minucci, "Inhibition of histone deacetylases in cancer therapy: lessons from leukaemia," British Journal of Cancer, vol. 114, no. 6, pp. 605-611, 2016.

[65] S. Y. Ler, L. E. N. G. CH, L. W. Khin et al., "HDAC1 and HDAC2 independently predict mortality in hepatocellular carcinoma by a competing risk regression model in a Southeast Asian population," Oncology Reports, vol. 34, no. 5, pp. 2238-2250, 2015.

[66] J. Yang, X. Jin, Y. Yan et al., "Inhibiting histone deacetylases suppresses glucose metabolism and hepatocellular carcinoma growth by restoring FBP1 expression," Scientific Reports, vol. 7, 2017.

[67] Y. H. Lee, D. Seo, K. J. Choi et al., "Antitumor effects in hepatocarcinoma of isoform-selective inhibition of HDAC2," Cancer Research, vol. 74, no. 17, pp. 4752-4761, 2014.

[68] H. Wu, T. Y. Yang, Y. Li et al., "Tumor necrosis factor receptor-associated factor 6 promotes hepatocarcinogenesis by interacting with histone deacetylase 3 to enhance c-Myc gene expression and protein stability," Hepatology, vol. 71, no. 1, pp. 148-163, 2020.

[69] H. Ji, Y. Zhou, X. Zhuang et al., "HDAC3 deficiency promotes liver cancer through a defect in $\mathrm{H} 3 \mathrm{~K} 9 \mathrm{ac} / \mathrm{H} 3 \mathrm{~K} 9 \mathrm{me} 3$ transition," Cancer Research, vol. 79, no. 14, pp. 3676-3688, 2019.

[70] Y. Hu, Q. Nie, M. Dai, F. Chen, and H. Wu, "Histone deacetylases inhibit the Snail2-mediated EMT during metastasis of hepatocellular carcinoma cells," Frontiers in Cell and Development Biology, vol. 8, 2020.

[71] Y. Hu, Y. Zheng, M. Dai et al., "G9a and histone deacetylases are crucial for Snail2-mediated E-cadherin repression and metastasis in hepatocellular carcinoma," Cancer Science, vol. 110, no. 11, pp. 3442-3452, 2019.

[72] M. Gu, T. B. Toh, L. Hooi, J. J. Lim, X. Zhang, and E. K. H. Chow, "Nanodiamond-mediated delivery of a G9a inhibitor for hepatocellular carcinoma therapy," ACS Applied Materials \& Interfaces, vol. 11, no. 49, pp. 45427-45441, 2019.

[73] C. Zhang, C. Yang, M. J. Feldman et al., "Vorinostat suppresses hypoxia signaling by modulating nuclear translocation of hypoxia inducible factor 1 alpha," Oncotarget, vol. 8, no. 34, pp. 56110-56125, 2017.

[74] R. Buurman, M. Sandbothe, B. Schlegelberger, and B. Skawran, "HDAC inhibition activates the apoptosome via Apaf1 upregulation in hepatocellular carcinoma," European Journal of Medical Research, vol. 21, no. 1, p. 26, 2016.

[75] S. Bhattacharya, D. Reddy, A. Ingle, B. Khade, and S. Gupta, "Brief Communication: Featured Article: Histone
$\mathrm{H} 2 \mathrm{~A}$ mono-ubiquitination and cellular transformation are inversely related in N-nitrosodiethylamine-induced hepatocellular carcinoma," Experimental Biology and Medicine, vol. 241, no. 16, pp. 1739-1744, 2016.

[76] P. Kotantaki and G. Mosialos, "The expression of tumor suppressor geneCyldis upregulated by histone deacetylace inhibitors in human hepatocellular carcinoma cell lines," Cell Biochemistry and Function, vol. 34, no. 7, pp. 465-468, 2016.

[77] S. Shin, M. Kim, S.-J. Lee, K.-S. Park, and C. H. Lee, "Trichostatin A sensitizes hepatocellular carcinoma cells to enhanced NK cell-mediated killing by regulating immune-related genes," Cancer Genomics \& Proteomics, vol. 14, no. 5, pp. 349-362, 2017.

[78] T. Chen, C. Gu, C. Xue et al., "LncRNA-uc002mbe.2 interacting with hnRNPA2B1 mediates AKT deactivation and p21 up-regulation induced by trichostatin in liver cancer cells," Frontiers in Pharmacology, vol. 8, p. 669, 2017.

[79] J. C. Chen, H. Y. Chuang, Y. J. Liao et al., "Enhanced cytotoxicity of human hepatocellular carcinoma cells following pretreatment with sorafenib combined with trichostatin A," Oncology Letters, vol. 17, no. 1, pp. 638-645, 2018.

[80] M. Fu, W. Shi, Z. Li, and H. Liu, "Activation of mPTPdependent mitochondrial apoptosis pathway by a novel pan HDAC inhibitor resminostat in hepatocellular carcinoma cells," Biochemical and Biophysical Research Communications, vol. 477, no. 4, pp. 527-533, 2016.

[81] X. Peng, D. Zhang, Z. Li, M. Fu, and H. Liu, "mTOR inhibition sensitizes human hepatocellular carcinoma cells to resminostat," Biochemical and Biophysical Research Communications, vol. 477, no. 4, pp. 556-562, 2016.

[82] J. Soukupova, E. Bertran, I. Peñuelas-Haro et al., "Resminostat induces changes in epithelial plasticity of hepatocellular carcinoma cells and sensitizes them to sorafenib-induced apoptosis," Oncotarget, vol. 8, no. 66, pp. 110367-110379, 2017.

[83] M. Bitzer, M. Horger, E. G. Giannini et al., "Resminostat plus sorafenib as second-line therapy of advanced hepatocellular carcinoma - the SHELTER study," Journal of Hepatology, vol. 65, no. 2, pp. 280-288, 2016.

[84] W. Y. Tak, B.-Y. Ryoo, H. Y. Lim et al., "Phase I/II study of first-line combination therapy with sorafenib plus resminostat, an oral HDAC inhibitor, versus sorafenib monotherapy for advanced hepatocellular carcinoma in east Asian patients," Investigational New Drugs, vol. 36, no. 6, pp. 1072-1084, 2018.

[85] S. Zopf, M. Ocker, D. Neureiter et al., "Inhibition of DNA methyltransferase activity and expression by treatment with the pan-deacetylase inhibitor panobinostat in hepatocellular carcinoma cell lines," BMC Cancer, vol. 12, no. 1, p. 386, 2012.

[86] P. Di Fazio, P. Waldegger, S. Jabari et al., "Autophagy-related cell death by pan-histone deacetylase inhibition in liver cancer," Oncotarget, vol. 7, no. 20, pp. 28998-29010, 2016.

[87] S. Maschauer, S. Gahr, M. Gandesiri et al., "In vivo monitoring of the anti-angiogenic therapeutic effect of the pandeacetylase inhibitor panobinostat by small animal PET in a mouse model of gastrointestinal cancers," Nuclear Medicine and Biology, vol. 43, no. 1, pp. 27-34, 2016.

[88] B. Liao, Y. Zhang, Q. Sun, and P. Jiang, "Vorinostat enhances the anticancer effect of oxaliplatin on hepatocellular carcinoma cells," Cancer Medicine, vol. 7, no. 1, pp. 196-207, 2018. 
[89] H. Park, I. Garrido-Laguna, A. Naing et al., "Phase I doseescalation study of the mTOR inhibitor sirolimus and the HDAC inhibitor vorinostat in patients with advanced malignancy," Oncotarget, vol. 7, no. 41, pp. 67521-67531, 2016.

[90] D. Llopiz, M. Ruiz, L. Villanueva et al., "Enhanced anti-tumor efficacy of checkpoint inhibitors in combination with the histone deacetylase inhibitor belinostat in a murine hepatocellular carcinoma model," Cancer Immunology, Immunotherapy, vol. 68, no. 3, pp. 379-393, 2019.

[91] S. Zheng, S. Guo, Q. Zhong et al., "Biocompatible boroncontaining prodrugs of belinostat for the Potential Treatment of Solid Tumors," ACS Medicinal Chemistry Letters, vol. 9, no. 2, pp. 149-154, 2018.

[92] M. Sanaei, F. Kavoosi, A. Roustazadeh, and H. Shahsavani, "In vitro effect of the histone deacetylase inhibitor valproic acid on viability and apoptosis of the PLC/PRF5 human hepatocellular carcinoma cell line," Asian Pacific Journal of Cancer Prevention, vol. 19, no. 9, pp. 2507-2510, 2018.

[93] J. Aucamp, H. C. Van Dyk, A. J. Bronkhorst, and P. J. Pretorius, "Valproic acid alters the content and function of the cellfree DNA released by hepatocellular carcinoma (HepG2) cells in vitro," Biochimie, vol. 140, pp. 93-105, 2017.

[94] J. I. Yu, C. Choi, S. W. Shin et al., "Valproic acid sensitizes hepatocellular carcinoma cells to proton therapy by suppressing NRF2 activation," Scientific Reports, vol. 7, no. 1, article 14986, 2017.

[95] S. K. Saha, Y. Yin, K. Kim et al., "Valproic acid induces endocytosis-mediated doxorubicin internalization and shows synergistic cytotoxic effects in hepatocellular carcinoma cells," International Journal of Molecular Sciences, vol. 18, no. 5, p. 1048, 2017.

[96] W. Zhu, Q. Liang, X. Yang, Y. Yu, X. Shen, and G. Sun, "Combination of sorafenib and valproic acid synergistically induces cell apoptosis and inhibits hepatocellular carcinoma growth via down-regulating Notch3 and pAkt," American Journal of Cancer Research, vol. 7, no. 12, pp. 2503-2514, 2017.

[97] D. H. Lee, J. Y. Nam, Y. Chang et al., "Synergistic effect of cytokine-induced killer cell with valproate inhibits growth of hepatocellular carcinoma cell in a mouse model," Cancer Biology \& Therapy, vol. 18, no. 1, pp. 67-75, 2016.

[98] M. Sanaei, F. Kavoosi, and H. Behjoo, "Effect of valproic acid and zebularine on SOCS- 1 and SOCS- 3 gene expression in colon carcinoma SW48 cell line," Experimental Oncology, vol. 42, no. 3, 2020.

[99] K. Pant, A. Saraya, and S. K. Venugopal, "Oxidative stress plays a key role in butyrate-mediated autophagy via Akt/mTOR pathway in hepatoma cells," Chemico-Biological Interactions, vol. 273, pp. 99-106, 2017.

[100] L.-A. Macfarlane and P. R. Murphy, "MicroRNA: biogenesis, function and role in cancer," Current Genomics, vol. 11, no. 7, pp. 537-561, 2010.

[101] J. O’Brien, H. Hayder, Y. Zayed, and C. Peng, "Overview of microRNA biogenesis, mechanisms of actions, and circulation," Frontiers in Endocrinology, vol. 9, p. 402, 2018.

[102] M.-H. Hu, C.-Y. Ma, X.-M. Wang et al., "MicroRNA-126 inhibits tumor proliferation and angiogenesis of hepatocellular carcinoma by down-regulating EGFL7 expression," Oncotarget, vol. 7, no. 41, pp. 66922-66934, 2016.

[103] B.-Q. Jing, Y. Ou, L. Zhao, Q. Xie, and Y.-X. Zhang, "Experimental study on the prevention of liver cancer angiogenesis via miR-126," European Review for Medical and Pharmacological Sciences, vol. 21, no. 22, pp. 5096-5100, 2017.

[104] C. Du, Z. Lv, L. Cao et al., "MiR-126-3p suppresses tumor metastasis and angiogenesis of hepatocellular carcinoma by targeting LRP6 and PIK3R2," Journal of Translational Medicine, vol. 12, no. 1, p. 259, 2014.

[105] C. Zhao, Y. Li, M. Zhang, Y. Yang, and L. Chang, "miR-126 inhibits cell proliferation and induces cell apoptosis of hepatocellular carcinoma cells partially by targeting Sox2," Human Cell, vol. 28, no. 2, pp. 91-99, 2015.

[106] L. Xiang, H. Ou, X. Liu et al., "Loss of tumor suppressor miR126 contributes to the development of hepatitis B virusrelated hepatocellular carcinoma metastasis through the upregulation of ADAM9," Tumor Biology, vol. 39, no. 6, p. $101042831770912,2017$.

[107] H. Chen, R. Miao, J. Fan et al., "Decreased expression of miR126 correlates with metastatic recurrence of hepatocellular carcinoma," Clinical \& Experimental Metastasis, vol. 30, no. 5, pp. 651-658, 2013.

[108] K. R. Babu and M. U. Muckenthaler, “miR-148a regulates expression of the transferrin receptor 1 in hepatocellular carcinoma," Scientific Reports, vol. 9, no. 1, article 1518, 2019.

[109] X. Chen, L. Bo, W. Lu, G. Zhou, and Q. Chen, "MicroRNA$148 \mathrm{~b}$ targets Rho-associated protein kinase 1 to inhibit cell proliferation, migration and invasion in hepatocellular carcinoma," Molecular Medicine Reports, vol. 13, no. 1, pp. 477$482,2016$.

[110] K. H. Jung, J. Zhang, C. Zhou et al., “Differentiation therapy for hepatocellular carcinoma: multifaceted effects of miR$148 \mathrm{a}$ on tumor growth and phenotype and liver fibrosis," Hepatology, vol. 63, no. 3, pp. 864-879, 2016.

[111] J.-P. Zhang, C. Zeng, L. Xu, J. Gong, J.-H. Fang, and S.M. Zhuang, "MicroRNA-148a suppresses the epithelial-mesenchymal transition and metastasis of hepatoma cells by targeting Met/Snail signaling," Oncogene, vol. 33, no. 31, pp. 4069-4076, 2014.

[112] X.-Y. Liu, Y.-J. He, Q.-H. Yang et al., "Induction of autophagy and apoptosis by miR-148a through the sonic hedgehog signaling pathway in hepatic stellate cells," American Journal of Cancer Research, vol. 5, no. 9, pp. 2569-2589, 2015.

[113] X.-R. Long, Y. He, C. Huang, and L. Jun, "MicroRNA-148a is silenced by hypermethylation and interacts with DNA methyltransferase 1 in hepatocellular carcinogenesis," International Journal of Oncology, vol. 44, no. 6, pp. 1915-1922, 2014.

[114] E. Callegari, L. D’Abundo, P. Guerriero et al., “miR-199a-3p modulates MTOR and PAK4 pathways and inhibits tumor growth in a hepatocellular carcinoma transgenic mouse model," Molecular Therapy-Nucleic Acids, vol. 11, pp. 485493, 2018.

[115] A. Varshney, J. J. Panda, A. K. Singh et al., “Targeted delivery of microRNA-199a-3p using self-assembled dipeptide nanoparticles efficiently reduces hepatocellular carcinoma in mice," Hepatology, vol. 67, no. 4, pp. 1392-1407, 2018.

[116] J. Guan, Z. Liu, M. Xiao et al., "MicroRNA-199a-3p inhibits tumorigenesis of hepatocellular carcinoma cells by targeting ZHX1/PUMA signal," American Journal of Translational Research, vol. 9, no. 5, pp. 2457-2465, 2017.

[117] C. Giovannini, F. Fornari, R. Dallo et al., "MiR-199-3p replacement affects E-cadherin expression through Notch1 targeting in hepatocellular carcinoma," Acta Histochemica, vol. 120, no. 2, pp. 95-102, 2018. 
[118] C. Xiao, X. Wan, H. Yu et al., "LncRNA-AB209371 promotes the epithelial-mesenchymal transition of hepatocellular carcinoma cells," Oncology Reports, vol. 41, no. 5, pp. 29572966, 2019.

[119] G. Huang, H. Shan, D. Li, B. Zhou, and P. Pang, "MiR-199a$5 \mathrm{p}$ suppresses tumorigenesis by targeting clathrin heavy chain in hepatocellular carcinoma," Cell Biochemistry and Function, vol. 35, no. 2, pp. 98-104, 2017.

[120] R. Gui, R. Huang, J.-H. Zhang, X.-H. Wen, and X.-M. Nie, "MicroRNA-199a-5p inhibits VEGF-induced tumorigenesis through targeting oxidored-nitro domain-containing protein 1 in human HepG2 cells," Oncology Reports, vol. 35, no. 4, pp. 2216-2222, 2016.

[121] S.-P. Jiang and Z.-R. Li, "MiR-503-5p regulates cell epithelialto-mesenchymal transition, metastasis and prognosis of hepatocellular carcinoma through inhibiting WEE1," European Review for Medical and Pharmacological Sciences, vol. 23, no. 5, pp. 2028-2037, 2019.

[122] B. Li, L. Liu, X. Li, and L. Wu, "miR-503 suppresses metastasis of hepatocellular carcinoma cell by targeting PRMT1," Biochemical and Biophysical Research Communications, vol. 464, no. 4, pp. 982-987, 2015.

[123] J. Zhou, Y. Tao, C. Peng, P. Gu, and W. Wang, "miR-503 regulates metastatic function through Rho guanine nucleotide exchanger factor 19 in hepatocellular carcinoma," The Journal of Surgical Research, vol. 188, no. 1, pp. 129-136, 2014.

[124] X. Yang, J. Zang, X. Pan et al., "miR-503 inhibits proliferation making human hepatocellular carcinoma cells susceptible to 5-fluorouracil by targeting EIF4E," Oncology Reports, vol. 37, no. 1, pp. 563-570, 2017.

[125] Y. Xiao, Q. Tian, J. He, M. Huang, C. Yang, and L. Gong, "MiR-503 inhibits hepatocellular carcinoma cell growth via inhibition of insulin-like growth factor 1 receptor," Oncotargets and Therapy, vol. 9, pp. 3535-3544, 2016.

[126] Y. Liu, J. Tan, S. Ou, J. Chen, and L. Chen, "MicroRNA-101$3 p$ suppresses proliferation and migration in hepatocellular carcinoma by targeting the HGF/c-Met pathway," Investigational New Drugs, vol. 38, no. 1, pp. 60-69, 2020.

[127] W. Si, Y. Zhao, J. Zhou, Q. Zhang, and Y. Zhang, "The coordination between ZNF217 and LSD1 contributes to hepatocellular carcinoma progress and is negatively regulated by miR-101," Experimental Cell Research, vol. 379, no. 1, pp. 1-10, 2019.

[128] J. Yang, Y. Lu, Y.-Y. Lin et al., "Vascular mimicry formation is promoted by paracrine TGF- $\beta$ and SDF1 of cancer-associated fibroblasts and inhibited by miR-101 in hepatocellular carcinoma," Cancer Letters, vol. 383, no. 1, pp. 18-27, 2016.

[129] X. Chen and N. Zhang, "Downregulation of lncRNA NEAT1_2 radiosensitizes hepatocellular carcinoma cells through regulation of miR-101-3p/WEE1 axis," Cell Biology International, vol. 43, no. 1, pp. 44-55, 2019.

[130] Y. Lei, Q. Wang, L. Shen, Y. Tao, and C. Liu, "MicroRNA-101 suppresses liver fibrosis by downregulating PI3K/Akt/mTOR signaling pathway," Clinics and Research in Hepatology and Gastroenterology, vol. 43, no. 5, pp. 575-584, 2019.

[131] F. Xu, J.-Z. Liao, G.-Y. Xiang et al., "MiR-101 and doxorubicin codelivered by liposomes suppressing malignant properties of hepatocellular carcinoma," Cancer Medicine, vol. 6, no. 3, pp. 651-661, 2017.

[132] S. Yan, X. Shan, K. Chen et al., "LINC00052/miR-101-3p axis inhibits cell proliferation and metastasis by targeting SOX9 in hepatocellular carcinoma," Gene, vol. 679, pp. 138-149, 2018.
[133] R. Hari and S. Parthasarathy, "Prediction of coding and noncoding RNA," in Encyclopedia of Bioinformatics and Computational Biology, pp. 230-240, Elsevier, 2019.

[134] L. Peng, X. Q. Yuan, C. Y. Zhang et al., "The emergence of long non-coding RNAs in hepatocellular carcinoma: an update," Journal of Cancer, vol. 9, no. 14, pp. 2549-2558, 2018.

[135] Z. S. Niu, X. J. Niu, and W. H. Wang, "Long non-coding RNAs in hepatocellular carcinoma: potential roles and clinical implications," World Journal of Gastroenterology, vol. 23, no. 32, pp. 5860-5874, 2017.

[136] X. Hu, J. Jiang, Q. Xu, C. Ni, L. Yang, and D. Huang, “A systematic review of long noncoding RNAs in hepatocellular carcinoma: molecular mechanism and clinical implications," BioMed Research International, vol. 2018, 13 pages, 2018.

[137] L. Zhang, J. Hu, M. Hao, and L. Bu, "Long noncoding RNA Linc01296 promotes hepatocellular carcinoma development through regulation of the miR-26a/PTEN axis," Biological Chemistry, vol. 401, no. 3, pp. 407-416, 2020.

[138] L. Fang, J. Sun, Z. Pan et al., "Long non-coding RNA NEAT1 promotes hepatocellular carcinoma cell proliferation through the regulation of miR-129-5p-VCP-I $\kappa \mathrm{B}$," American Journal of Physiology-Gastrointestinal and Liver Physiology, vol. 313, no. 2, pp. G150-G156, 2017.

[139] N. Zhang and X. Chen, "Long non-coding RNA LINC00346 promotes hepatocellular carcinoma progression through the Wnt/ $\beta$-catenin signaling pathway," SSRN Electronic Journal, 2019.

[140] K. Cai, T. Li, L. Guo et al., "Long non-coding RNA LINC00467 regulates hepatocellular carcinoma progression by modulating miR-9-5p/PPARA expression," Open Biology, vol. 9, no. 9, p. 190074, 2019.

[141] H. Wang, L. Liang, Q. Dong et al., "Long noncoding RNA miR503HG, a prognostic indicator, inhibits tumor metastasis by regulating the HNRNPA2B1/NF- $\kappa \mathrm{B}$ pathway in hepatocellular carcinoma," Theranostics, vol. 8, no. 10, pp. 28142829, 2018.

[142] Y. Wei, Z. Wang, Y. Zong, D. Deng, P. Chen, and J. Lu, "LncRNA MFI2-AS1 promotes HCC progression and metastasis by acting as a competing endogenous RNA of miR-134 to upregulate FOXM1 expression," Biomedicine \& Pharmacotherapy, vol. 125, article 109890, 2020.

[143] Z. Zhang, L. Yang, X. Yao, M. Yang, and G. Li, "LncRNAZNF281 interacts with miR-539 to promote hepatocellular carcinoma cell invasion and migration," Cancer Biotherapy \& Radiopharmaceuticals, vol. 35, no. 2, pp. 137-142, 2020.

[144] W. Zhang, Y. Liu, Y. Fu et al., "Long non-coding RNA LINC00160 functions as a decoy of microRNA-132 to mediate autophagy and drug resistance in hepatocellular carcinoma via inhibition of PIK3R3," Cancer Letters, vol. 478, pp. 22-33, 2020.

[145] L. H. Luo, M. Jin, L. Q. Wang et al., "Long noncoding RNA TCL6 binds to miR-106a-5p to regulate hepatocellular carcinoma cells through PI3K/AKT signaling pathway," Journal of Cellular Physiology, vol. 235, no. 9, pp. 6154-6166, 2020.

[146] S. Wu, S. Chen, N. Lin, and J. Yang, "Long non-coding RNA SUMO1P3 promotes hepatocellular carcinoma progression through activating Wnt $/ \beta$-catenin signalling pathway by targeting miR-320a," Journal of Cellular and Molecular Medicine, vol. 24, no. 5, pp. 3108-3116, 2020. 
[147] F. Wei, L. Yang, D. Jiang et al., "Long noncoding RNA DUXAP8 contributes to the progression of hepatocellular carcinoma via regulating miR-422a/PDK2 axis," Cancer Medicine, vol. 9, no. 7, pp. 2480-2490, 2020.

[148] L. Sun, L. Wang, T. Chen et al., "LncRNA RUNX1-IT1 which is downregulated by hypoxia-driven histone deacetylase 3 represses proliferation and cancer stem-like properties in hepatocellular carcinoma cells," Cell Death \& Disease, vol. 11, no. 2, pp. 1-5, 2020.

[149] A. Qu and Q. Yang, "LncRNA SNHG1 promotes cell progression and metastasis via sponging miR-377-3p in hepatocellular carcinoma," Neoplasma, vol. 67, no. 3, pp. 557-566, 2020.

[150] H. L. Zhu, R. Yuan, H. Wang, C. Li, and J. Wei, "LncRNA MINCR promotes the development of liver cancer by regulating microRNA-107/ $\beta$-catenin," Journal of BU ON, vol. 25, no. 2, pp. 972-980, 2020.

[151] Z. Wen, L. Lian, H. Ding et al., "LncRNA ANCR promotes hepatocellular carcinoma metastasis through upregulating HNRNPA1 expression," RNA Biology, vol. 17, no. 3, pp. 381-394, 2020.

[152] J. T. Zhao, B. J. Chi, Y. Sun et al., "LINC00174 is an oncogenic lncRNA of hepatocellular carcinoma and regulates miR320/S100A10 axis," Cell Biochemistry and Function, vol. 38, no. 7, pp. 859-869, 2020.

[153] H. Wang, Q. Guo, K. B. Nampoukime, P. Yang, and K. Ma, "Long non-coding RNA LINC00467 drives hepatocellular carcinoma progression via inhibiting NR4A3," Journal of Cellular and Molecular Medicine, vol. 24, no. 7, pp. 3822-3836, 2020.

[154] L. H. Mao, S. Y. Chen, X. Q. Li et al., "LncRNA-LALR1 upregulates small nucleolar RNA SNORD72 to promote growth and invasion of hepatocellular carcinoma," Aging, vol. 12, no. 5, pp. 4527-4546, 2020.

[155] H. Q. Bi, Z. H. Li, and H. Zhang, "Long noncoding RNA HAND2-AS1 reduced the viability of hepatocellular carcinoma via targeting microRNA-300/SOCS5 axis," Hepatobiliary \& Pancreatic Diseases International, 2020.

[156] Y. Chi, Z. Gong, H. Xin, Z. Wang, and Z. Liu, "Long noncoding RNA lncARSR promotes nonalcoholic fatty liver disease and hepatocellular carcinoma by promoting YAP1 and activating the IRS2/AKT pathway," Journal of Translational Medicine, vol. 18, no. 1, p. 126, 2020.

[157] W. Pan, N. Zhang, W. Liu et al., "The long noncoding RNAGAS8-AS1suppresses hepatocarcinogenesis by epigenetically activating the tumor suppressorGAS8," The Journal of Biological Chemistry, vol. 293, no. 44, pp. 17154-17165, 2018.

[158] R. Shang, M. Wang, B. Dai et al., "Long noncoding RNASLC2A1-AS1regulates aerobic glycolysis and progression in hepatocellular carcinoma via inhibiting the STAT3/ FOXM1/GLUT1 pathway," Molecular Oncology, vol. 14, no. 6, pp. 1381-1396, 2020.

[159] C. Liu, M. Zhang, J. Zhao et al., "LncRNA FOXD3-AS1 mediates AKT pathway to promote growth and invasion in hepatocellular carcinoma through regulating RICTOR," Cancer Biotherapy \& Radiopharmaceuticals, vol. 35, no. 4, pp. 292300, 2020.

[160] P. A. Hu, Y. Y. Miao, S. Yu, and N. Guo, "Long non-coding RNA SNHG5 promotes human hepatocellular carcinoma progression by regulating miR-363-3p/RNF38 axis," European Review for Medical and Pharmacological Sciences, vol. 24, no. 7, pp. 3592-3604, 2020.
[161] W. Xuan, C. Zhou, and G. You, "LncRNA LINC00668 promotes cell proliferation, migration, invasion ability and EMT process in hepatocellular carcinoma by targeting miR532-5p/YY1 axis," Bioscience Reports, vol. 40, no. 5, 2020.

[162] J. Gao, C. Dai, X. Yu, X. B. Yin, and F. Zhou, "LncRNA LEF1-AS1 silencing diminishes EZH2 expression to delay hepatocellular carcinoma development by impairing CEBPBinteraction with CDCA7," Cell Cycle, vol. 19, no. 8, pp. 870883, 2020.

[163] C. Shi, Q. Yang, S. Pan et al., "LncRNA OIP5-AS1 promotes cell proliferation and migration and induces angiogenesis via regulating miR-3163/VEGFA in hepatocellular carcinoma," Cancer Biology \& Therapy, vol. 21, no. 7, pp. 604-614, 2020.

[164] W. J. Huang, X. P. Tian, S. X. Bi et al., "The $\beta$-catenin/TCF-4LINC01278-miR-1258-Smad2/3 axis promotes hepatocellular carcinoma metastasis," Oncogene, vol. 39, no. 23, pp. 4538-4550, 2020.

[165] W. Zhang, L. Han, P. Xing et al., "LncRNA RHPN1-AS1 accelerates proliferation, migration, and invasion via regulating miR-485-5p/BSG axis in hepatocellular carcinoma," Naunyn-Schmiedeberg's Archives of Pharmacology, vol. 21, pp. 19, 2020.

[166] X. Guo and Y. Wang, "LncRNA TMPO-AS1 promotes hepatocellular carcinoma cell proliferation, migration and invasion through sponging miR-329-3p to stimulate FOXK1mediated AKT/mTOR signaling pathway," Cancer Medicine, vol. 9, no. 14, pp. 5235-5246, 2020.

[167] Y. Liang, D. Zhang, T. Zheng et al., "IncRNA-SOX2OT promotes hepatocellular carcinoma invasion and metastasis through miR-122-5p-mediated activation of PKM2," Oncogene, vol. 9, no. 5, pp. 1-2, 2020.

[168] B. Wang, J. Xian, J. Zang et al., "Long non-coding RNA FENDRR inhibits proliferation and invasion of hepatocellular carcinoma by down-regulating glypican-3 expression," Biochemical and Biophysical Research Communications, vol. 509, no. 1, pp. 143-147, 2019.

[169] M. M. Wu, W. D. Shen, C. W. Zou, H. J. Chen, and H. M. Guo, "LncRNA-HEIH suppresses hepatocellular carcinoma cell growth and metastasis by up-regulating miR-199a-3p," European Review for Medical and Pharmacological Sciences, vol. 24, no. 11, pp. 6031-6038, 2020.

[170] J. H. Wu, K. Xu, J. H. Liu et al., "LncRNA MT1JP inhibits the malignant progression of hepatocellular carcinoma through regulating AKT," European Review for Medical and Pharmacological Sciences, vol. 24, no. 12, pp. 6647-6656, 2020.

[171] Y. S. Ma, K. J. Chu, C. C. Ling, T. M. Wu, and X. C. Zhu, "Long noncoding RNA OIP5-AS1 promotes the progression of liver hepatocellular carcinoma via regulating the hsamiR-26a-3p/EPHA2 axis," Molecular Therapy-Nucleic Acids, vol. 21, pp. 229-241, 2020.

[172] C. Cao, Q. Zhong, L. Lu et al., "Long noncoding RNA MSCAS1 promotes hepatocellular carcinoma oncogenesis via inducing the expression of phosphoglycerate kinase 1," Cancer Medicine, vol. 9, no. 14, pp. 5174-5184, 2020.

[173] G. Zhang, X. Chen, L. Ma et al., "LINC01419 facilitates hepatocellular carcinoma growth and metastasis through targeting EZH2-regulated RECK," Aging, vol. 12, no. 11, pp. 11071-11084, 2020.

[174] W. Hu, H. Feng, X. Xu et al., "Long noncoding RNA FOXD2AS1 aggravates hepatocellular carcinoma tumorigenesis by regulating the miR-206/MAP3K1 axis," Cancer Medicine, vol. 9, no. 15 , pp. 5620-5631, 2020. 
[175] W. Li, J. Ge, J. Xie, J. Yang, J. Chen, and T. He, "LncRNATUG1promotes hepatocellular carcinoma migration and invasion via targeting miR-137/AKT2 axis," Cancer Biotherapy \& Radiopharmaceuticals, 2020.

[176] S. J. Tang and J. B. Yang, "LncRNA SNHG14 aggravates invasion and migration as ceRNA via regulating miR-6563p/SIRT5 pathway in hepatocellular carcinoma," Molecular and Cellular Biochemistry, vol. 473, no. 1-2, pp. 143-153, 2020.

[177] Y. Xu, Y. Liu, Z. Li et al., "Long non-coding RNA H19 is involved in sorafenib resistance in hepatocellular carcinoma by upregulating miR-675," Oncology Reports, vol. 44, no. 1, pp. 165-173, 2020.

[178] H. Topel, E. Bagirsakci, D. Comez, G. Bagci, G. Cakan-Akdogan, and N. Atabey, "IncRNA HOTAIR overexpression induced downregulation of c-Met signaling promotes hybrid epithelial/mesenchymal phenotype in hepatocellular carcinoma cells," Cell Communication and Signaling: CCS, vol. 18, no. 1, p. 110, 2020.

[179] Y. Pan, T. Qin, S. Yin, X. Zhang, X. Gao, and L. Mu, "Long non-coding RNA UC001kfo promotes hepatocellular carcinoma proliferation and metastasis by targeting $\alpha$-SMA," Biomedicine \& Pharmacotherapy, vol. 87, pp. 669-677, 2017.

[180] Y. Zou, Z. Sun, and S. Sun, "LncRNA HCG18 contributes to the progression of hepatocellular carcinoma via miR-2143p/CENPM axis," Journal of Biochemistry, vol. 168, no. 5, 2020.

[181] S. Kong, H. Xue, Y. Li et al., "The long noncoding RNA OTUD6B-AS1 enhances cell proliferation and the invasion of hepatocellular carcinoma cells through modulating GSKIP/Wnt/ $\beta$-catenin signalling via the sequestration of miR-664b-3p," Experimental Cell Research, vol. 395, no. 1, p. 112180, 2020.

[182] C. Sun, S. Huang, Y. Hou et al., "Long noncoding RNA AC092171.4 promotes hepatocellular carcinoma progression by sponging microRNA-1271 and upregulating GRB2," Aging, vol. 12, no. 14, pp. 14141-14156, 2020.

[183] X. Qian, S. Li, Z. Yang, and J. Zhang, "The long non-coding RNA HLNC1 potentiates hepatocellular carcinoma progression via interaction withUSP49," Journal of Clinical Laboratory Analysis, vol. 34, no. 11, 2020.

[184] Y. Duan, J. Chen, Y. Yang, Z. Qu, Y. Lu, and D. Sun, "LncRNA HOTAIR contributes Taxol-resistance of hepatocellular carcinoma cells via activating AKT phosphorylation by down-regulating miR-34a," Bioscience Reports, vol. 40, no. 7, 2020.

[185] Y. A. Chen, L. Cheng, Y. Zhang, L. Peng, and H. G. Yang, "LncRNA RUSC1-AS1 promotes the proliferation of hepatocellular carcinoma cells through modulating NOTCH signaling," Neoplasma, 2020.

[186] Y. Z. Lun, Z. P. Pan, S. A. Liu et al., "The peptide encoded by a novel putative lncRNA HBVPTPAP inducing the apoptosis of hepatocellular carcinoma cells by modulating JAK/STAT signaling pathways," Virus Research, vol. 287, p. 198104, 2020.

[187] H. Zhang, H. B. Xu, E. Kurban, and H. W. Luo, "LncRNA SNHG14 promotes hepatocellular carcinoma progression via H3K27 acetylation activated PABPC1 by PTEN signaling," Cell Death \& Disease, vol. 11, no. 8, pp. 1-3, 2020.

[188] X. Wang, M. L. Cheng, Y. Gong, W. J. Ma, B. Li, and Y. Z. Jiang, "LncRNA DANCR promotes ATG7 expression to accelerate hepatocellular carcinoma cell proliferation and autophagy by sponging miR-222-3p," European Review for Medical and Pharmacological Sciences, vol. 24, no. 17, pp. 8778-8787, 2020.

[189] Z. Liu, H. Mo, L. Sun et al., "Long noncoding RNA PICSAR/miR-588/EIF6 axis regulates tumorigenesis of hepatocellular carcinoma by activating PI3K/AKT/mTOR signaling pathway," Cancer Science, vol. 111, no. 11, pp. 4118-4128, 2020.

[190] X. Xu, Y. Lou, J. Tang et al., “The long non-coding RNA LincGALH promotes hepatocellular carcinoma metastasis via epigenetically regulating Gankyrin," Cell Death \& Disease, vol. 10, no. 2, p. 86, 2019.

[191] Y. Liu, W. Yan, D. Zhou, G. Jin, and X. Cheng, "Long noncoding RNA HOXA11-AS accelerates cell proliferation and epithelial-mesenchymal transition in hepatocellular carcinoma by modulating the miR-506-3p/Slug axis," International Journal of Molecular Medicine, vol. 46, no. 5, pp. 1805-1815, 2020.

[192] Z. Wu, Z. H. Wei, and S. H. Chen, "LncUBE2R2-AS1 acts as a microRNA sponge of miR-302b to promote HCC progression via activation EGFR-PI3K-AKT signaling pathway," Cell Cycle, vol. 19, no. 19, pp. 2426-2435, 2020.

[193] H. He, Y. Wang, P. Ye et al., "Long noncoding RNA ZFPM2AS1 acts as a miRNA sponge and promotes cell invasion through regulation of miR-139/GDF10 in hepatocellular carcinoma," Journal of Experimental \& Clinical Cancer Research, vol. 39, no. 1, p. 159, 2020.

[194] J. Gao, C. Dai, X. Yu, X. Yin, and F. Zhou, "Long noncoding RNA LEF1-AS1 acts as a microRNA-10a-5p regulator to enhance MSI1 expression and promote chemoresistance in hepatocellular carcinoma cells through activating AKT signaling pathway," Journal of Cellular Biochemistry, vol. 12, 2020.

[195] Y. Li, D. Guo, G. Lu et al., "LncRNA SNAI3-AS1 promotes PEG10-mediated proliferation and metastasis via decoying of miR-27a-3p and miR-34a-5p in hepatocellular carcinoma," Cell Death \& Disease, vol. 11, no. 8, 2020.

[196] C. Wang, H. Zi, Y. Wang, B. Li, Z. Ge, and X. Ren, "Retracted article: LncRNACASC15promotes tumour progression throughSOX4/Wnt/ $\beta$-catenin signalling pathway in hepatocellular carcinoma," Artificial Cells, Nanomedicine, and Biotechnology, vol. 48, no. 1, pp. 763-769, 2020.

[197] J. Zhang, X. Zhao, X. Ma, Z. Yuan, and M. Hu, "KCNQ1OT1 contributes to sorafenib resistance and programmed deathligand-1-mediated immune escape via sponging miR-506 in hepatocellular carcinoma cells," International Journal of Molecular Medicine, vol. 46, no. 5, pp. 1794-1804, 2020.

[198] L. Lxia, B. Liu, J. Yu, Z. Dyun, S. Jhong, and P. Liang, "SP1induced upregulation of lncRNA CTBP1-AS2 accelerates the hepatocellular carcinoma tumorigenesis through targeting CEP55 via sponging miR-195-5p," Biochemical and Biophysical Research Communications, 2020.

[199] Y. Cao, F. Zhang, H. Wang et al., "LncRNA MALAT1 mediates doxorubicin resistance of hepatocellular carcinoma by regulating miR-3129-5p/Noval axis," Molecular and Cellular Biochemistry, vol. 1, 2020.

[200] F. Chen, Y. Wang, Y. Cheng et al., “AC006262.5/miR-7855$5 \mathrm{p} / \mathrm{BPY} 2 \mathrm{C}$ axis facilitates hepatocellular carcinoma proliferation and migration," Biochemistry and Cell Biology, 2020.

[201] Q. Y. Li, K. Yang, F. G. Liu et al., "Long noncoding RNA CASC2c inhibited cell proliferation in hepatocellular carcinoma by inactivated ERK1/2 and $\mathrm{Wnt} / \beta$-catenin signaling 
pathway," Clinical \& Translational Oncology, vol. 22, no. 3, pp. 302-310, 2020.

[202] B. W. Chen, Y. Zhou, T. Wei et al., "IncRNA-POIR promotes epithelial-mesenchymal transition and suppresses sorafenib sensitivity simultaneously in hepatocellular carcinoma by sponging miR-182-5p," Journal of Cellular Biochemistry, 2020.

[203] H. Wu, T. T. Liu, Y. M. Feng et al., "Prognostic effect of a novel long noncoding RNA signature and comparison with clinical staging systems for patients with hepatitis B virusrelated hepatocellular carcinoma after hepatectomy," Journal of Digestive Diseases, 2020.

[204] T. Wan, J. Zheng, R. Yao, S. Yang, W. Zheng, and P. Zhou, "LncRNA DDX11-AS1 accelerates hepatocellular carcinoma progression via the miR-195-5p/MACC1 pathway," Annals of Hepatology, vol. 19, 2020.

[205] G. Yang, L. Zhou, Q. Xu et al., "LncRNA KCNQ1OT1 inhibits the radiosensitivity and promotes the tumorigenesis of hepatocellular carcinoma via the miR-146a-5p/ACER3 axis," Cell Cycle, vol. 19, no. 19, pp. 2519-2529, 2020.

[206] D. Xu, X. Liu, J. Wu et al., "LncRNA WWOX-AS1 sponges miR-20b-5p in hepatocellular carcinoma and represses its progression by upregulating WWOX," Cancer Biology \& Therapy, vol. 21, no. 10, pp. 927-936, 2020.

[207] Y. Li, W. Zhuang, M. Huang, and X. Li, "Long noncoding RNA DDX11-AS1 epigenetically represses LATS2 by interacting with EZH2 and DNMT1 in hepatocellular carcinoma," Biochemical and Biophysical Research Communications, vol. 514, no. 4, pp. 1051-1057, 2019.

[208] T. Yi, T. Wang, Y. Shi et al., "Long noncoding RNA $91 \mathrm{H}$ overexpression contributes to the growth and metastasis of HCC by epigenetically positively regulating IGF2 expression," Liver International, vol. 40, no. 2, pp. 456-467, 2019.

[209] H. L. Chang, O. A. Bamodu, J. R. Ong, W. H. Lee, C. T. Yeh, and J. T. Tsai, "Targeting the epigenetic non-coding RNA MALAT1/Wnt signaling axis as a therapeutic approach to suppress stemness and metastasis in hepatocellular carcinoma," Cell, vol. 9, no. 4, 2020.

[210] S. C. Xie, J. Q. Zhang, X. L. Jiang et al., "LncRNA CRNDE facilitates epigenetic suppression of CELF2 and LATS2 to promote proliferation, migration and chemoresistance in hepatocellular carcinoma," Cell Death \& Disease, vol. 11, no. 8, pp. 1-7, 2020.

[211] X. Xu, J. Gu, X. Ding et al., "LINC00978 promotes the progression of hepatocellular carcinoma by regulating EZH2mediated silencing of p21 and E-cadherin expression," Cell Death \& Disease, vol. 10, no. 10, pp. 1-5, 2019.

[212] D. Gong, P.-C. Feng, X.-F. Ke et al., "Silencing long noncoding RNA LINC01224 inhibits hepatocellular carcinoma progression via microRNA-330-5p-induced inhibition of CHEK1," Molecular Therapy-Nucleic Acids, vol. 19, pp. 482-497, 2020.

[213] H. L. Zhou, Y. F. Zhou, and Z. T. Feng, "Long noncoding RNA ZFAS1 promotes hepatocellular carcinoma proliferation by epigenetically repressing miR-193a-3p," European Review for Medical and Pharmacological Sciences, vol. 23, no. 22, pp. 9840-9847, 2019.

[214] Y. Ji, H. Sun, H. Liang et al., "Evaluation of lncrna anril potential in hepatic cancer progression," Journal of Environmental Pathology, Toxicology and Oncology, vol. 38, no. 2, pp. 119-131, 2019.
[215] J. Bayo, E. J. Fiore, L. M. Dominguez et al., “A comprehensive study of epigenetic alterations in hepatocellular carcinoma identifies potential therapeutic targets," Journal of Hepatology, vol. 71, no. 1, pp. 78-90, 2019.

[216] C. T. Law, L. Wei, F. H. Tsang et al., "HELLS regulates chromatin remodeling and epigenetic silencing of multiple tumor suppressor genes in human hepatocellular carcinoma," Нераtology, vol. 69, no. 5, pp. 2013-2030, 2019.

[217] Y. Zheng, Q. Huang, Z. Ding et al., "Genome-wide DNA methylation analysis identifies candidate epigenetic markers and drivers of hepatocellular carcinoma," Briefings in Bioinformatics, vol. 19, no. 1, 2018.

[218] J. Lu, T. Tan, L. Zhu, H. Dong, and R. Xian, "Hypomethylation causes MIR21 overexpression in tumors," Molecular Therapy-Oncolytics, vol. 18, pp. 47-57, 2020.

[219] F. Xu, L. Zhang, Y. Xu et al., "Hypermethylation of scand3 and myolg gene are potential diagnostic biomarkers for hepatocellular carcinoma," Cancers, vol. 12, no. 8, pp. 1-15, 2020.

[220] J. L. Peng, J. Z. Wu, G. J. Li et al., “Association of RASSF1A hypermethylation with risk of $\mathrm{HBV} / \mathrm{HCV}$-induced hepatocellular carcinoma: a meta-analysis," Pathology Research and Practice, vol. 216, no. 10, article 153099, 2020.

[221] M. C. Yu, C. W. Lee, C. H. Lin et al., "Differential hypermethylation of the VTRNA2-1 promoter in hepatocellular carcinoma as a prognostic factor: tumor marker prognostic study," International Journal of Surgery, vol. 79, pp. 282289, 2020.

[222] N. Sun, J. Zhang, C. Zhang, B. Zhao, and A. O. Jiao, “DNMTs inhibitor SGI-1027 induces apoptosis in Huh7 human hepatocellular carcinoma cells," Oncology Letters, vol. 16, no. 5, pp. 5799-5806, 2018.

[223] M. Bárcena-Varela, S. Caruso, S. Llerena et al., "Dual targeting of histone methyltransferase G9a and DNAmethyltransferase 1 for the treatment of experimental hepatocellular carcinoma," Hepatology, vol. 69, no. 2, pp. 587603, 2019.

[224] D. Carlisi, M. Lauricella, A. D’Anneo et al., “The histone deacetylase inhibitor suberoylanilide hydroxamic acid sensitises human hepatocellular carcinoma cells to TRAIL-induced apoptosis by TRAIL-DISC activation," European Journal of Cancer, vol. 45, no. 13, pp. 2425-2438, 2009.

[225] B. He, L. Dai, X. Zhang et al., "The HDAC inhibitor quisinostat (JNJ-26481585) supresses hepatocellular carcinoma alone and synergistically in combination with sorafenib by G0/G1 phase arrest and apoptosis induction," International Journal of Biological Sciences, vol. 14, no. 13, pp. 1845-1858, 2018.

[226] W. J. Sun, H. Huang, B. He et al., "Romidepsin induces G2/M phase arrest via Erk/cdc25C/cdc2/cyclinB pathway and apoptosis induction through JNK/c-Jun/caspase3 pathway in hepatocellular carcinoma cells," Biochemical Pharmacology, vol. 127, pp. 90-100, 2017.

[227] J. L. Jilek, Q.-Y. Zhang, M.-J. Tu et al., "Bioengineered Let-7c inhibits orthotopic hepatocellular carcinoma and improves overall survival with minimal immunogenicity," Molecular Therapy-Nucleic Acids, vol. 14, pp. 498-508, 2019.

[228] L. Guo, B. Li, M. Miao, J. Yang, and J. Ji, “MicroRNA-663b targets GAB2 to restrict cell proliferation and invasion in hepatocellular carcinoma," Molecular Medicine Reports, vol. 19, no. 4, pp. 2913-2920, 2019. 
[229] C. Yang, M. Yin, G. Xu et al., "Biodegradable polymers as a noncoding miRNA nanocarrier for multiple targeting therapy of human hepatocellular carcinoma," Advanced Healthcare Materials, vol. 8, no. 8, p. 1801318, 2019.

[230] H. Huang, Y. Zhu, and S. Li, "MicroRNA-122 mimic transfection contributes to apoptosis in HepG2 cells," Molecular Medicine Reports, vol. 12, no. 5, pp. 6918-6924, 2015.

[231] Y. Shao, X. Song, W. Jiang et al., "MicroRNA-621 acts as a tumor radiosensitizer by directly targeting SETDB1 in hepatocellular carcinoma," Molecular Therapy, vol. 27, no. 2, pp. 355-364, 2019.

[232] X. Jiang and X. Shen, "Knockdown of miR-299-5p inhibits the progression of hepatocellular carcinoma by targeting SIAH1," Bulletin du Cancer, vol. 105, no. 10, pp. 873-883, 2018.

[233] S. Han, Z. Liu, Y. Wang et al., "MicroRNA-577 inhibits the migration and invasion of hepatocellular carcinoma cells by targeting homeobox A1," Oncology Reports, vol. 39, no. 6, pp. 2987-2995, 2018.

[234] C. Luo, D. Yin, H. Zhan et al., "MicroRNA-501-3p suppresses metastasis and progression of hepatocellular carcinoma through targeting LIN7A," Cell Death \& Disease, vol. 9, no. 5, p. 535, 2018.

[235] H. Fu, J. Zhang, T. Pan, S. Ai, L. Tang, and F. Wang, "miR378a enhances the sensitivity of liver cancer to sorafenib by targeting VEGFR, PDGFR $\beta$ and c-Raf," Molecular Medicine Reports, vol. 17, no. 3, 2018.

[236] Y. Chu, M. Jiang, F. du et al., "miR-204-5p suppresses hepatocellular cancer proliferation by regulating homeoprotein SIX1 expression," FEBS Open Bio, vol. 8, no. 2, pp. 189-200, 2018.

[237] Y. Ye, J. Zhuang, G. Wang et al., "MicroRNA-495 suppresses cell proliferation and invasion of hepatocellular carcinoma by directly targeting insulin-like growth factor receptor-1," Experimental and Therapeutic Medicine, vol. 15, no. 1, pp. 1150-1158, 2018.

[238] D. Jiang, W. C. Cho, Z. Li et al., "MiR-758-3p suppresses proliferation, migration and invasion of hepatocellular carcinoma cells via targeting MDM2 and mTOR," Biomedicine \& Pharmacotherapy, vol. 17, no. 3, pp. 535-544, 2017.

[239] S. Zhang, Q. Liu, Q. Zhang, and L. Liu, "MicroRNA-30a-5p suppresses proliferation, invasion and tumor growth of hepatocellular cancer cells via targeting FOXA1," Oncology Letters, vol. 14, no. 4, pp. 5018-5026, 2017.

[240] L. Yang, F. Peng, J. Qin, H. Zhou, and B. Wang, "Downregulation of microRNA-196a inhibits human liver cancer cell proliferation and invasion by targeting FOXO1," Oncology Reports, vol. 38, no. 4, pp. 2148-2154, 2017.

[241] K. Zhou, X. Luo, Y. Wang, D. Cao, and G. Sun, "MicroRNA30a suppresses tumor progression by blocking Ras/Raf/ MEK/ERK signaling pathway in hepatocellular carcinoma," Biomedicine \& Pharmacotherapy, vol. 93, pp. 1025-1032, 2017.

[242] S. Hu, Y. Ran, W. Chen, Y. Zhang, and Y. Xu, "MicroRNA326 inhibits cell proliferation and invasion, activating apoptosis in hepatocellular carcinoma by directly targeting LIM and SH3 protein 1," Oncology Reports, vol. 38, no. 3, pp. 1569-1578, 2017.

[243] Q. Li, S. Li, Y. Wu, and F. Gao, "miRNA-708 functions as a tumour suppressor in hepatocellular carcinoma by targeting SMAD3," Oncology Letters, vol. 14, no. 2, pp. 2552-2558, 2017.
[244] X. Ma, B. Zhuang, and W. Li, "MicroRNA-296-5p downregulated AKT2 to inhibit hepatocellular carcinoma cell proliferation, migration and invasion," Molecular Medicine Reports, vol. 16, no. 2, pp. 1565-1572, 2017.

[245] Y. Liu, H. Huang, M. Liu, Q. Wu, W. Li, and J. Zhang, "MicroRNA-24-1 suppresses mouse hepatoma cell invasion and metastasis via directly targeting O-GlcNAc transferase," Biomedicine \& Pharmacotherapy, vol. 91, pp. 731-738, 2017.

[246] F. Cartier, E. Indersie, S. Lesjean et al., "New tumor suppressor microRNAs target glypican-3 in human liver cancer," Oncotarget, vol. 8, no. 25, pp. 41211-41226, 2017.

[247] G. Jiang, L. Wen, W. Deng, Z. Jian, and H. Zheng, "Regulatory role of miR-211-5p in hepatocellular carcinoma metastasis by targeting ZEB2," Biomedicine \& Pharmacotherapy, vol. 90, pp. 806-812, 2017.

[248] C. Zuo, X. Sheng, Z. Liu et al., "MicroRNA-138 enhances TRAIL-induced apoptosis through interferon-stimulated gene 15 downregulation in hepatocellular carcinoma cells," Tumor Biology, vol. 39, no. 6, 2017.

[249] W. Wang, H. Zhang, M. Tang et al., "MicroRNA-592 targets IGF-1R to suppress cellular proliferation, migration and invasion in hepatocellular carcinoma," Oncology Letters, vol. 13, no. 5, pp. 3522-3528, 2017.

[250] M. Li, Y. Yang, Y. Kuang et al., "miR-365 induces hepatocellular carcinoma cell apoptosis through targeting Bcl-2," Experimental and Therapeutic Medicine, vol. 13, no. 5, pp. 2279-2285, 2017.

[251] M. Zhang, M. Li, N. Li et al., "miR-217 suppresses proliferation, migration, and invasion promoting apoptosis via targeting MTDH in hepatocellular carcinoma," Oncology Reports, vol. 37, no. 3, pp. 1772-1778, 2017.

[252] L. Zhou, S. Liu, M. Han et al., "MicroRNA-185 induces potent autophagy via AKT signaling in hepatocellular carcinoma," Tumor Biology, vol. 39, no. 2, 2017.

[253] H. Ge, D. Zou, Y. Wang, H. Jiang, and L. Wang, "MicroRNA377 downregulates $\mathrm{Bcl}-\mathrm{xL}$ and increases apoptosis in hepatocellular carcinoma cells," Oncology Research Featuring Preclinical and Clinical Cancer Therapeutics, vol. 25, no. 1, pp. 29-34, 2017.

[254] L.-J. Luo, L.-P. Zhang, C.-Y. Duan et al., "The inhibition role of miR-22 in hepatocellular carcinoma cell migration and invasion via targeting CD147," Cancer Cell International, vol. 17, no. 1, 2017.

[255] X. Wei, C. Tang, X. Lu et al., "MiR-101 targets DUSP1 to regulate the TGF- $\beta$ secretion in sorafenib inhibits macrophageinduced growth of hepatocarcinoma," Oncotarget, vol. 6, no. 21, pp. 18389-18405, 2015.

[256] F. Zheng, Y.-J. Liao, M.-Y. Cai et al., "Systemic delivery of microRNA-101 potently inhibits hepatocellular carcinoma in vivo by repressing multiple targets," PLoS Genetics, vol. 11, no. 2, article e1004873, 2015.

[257] L. Xu, S. Beckebaum, S. Iacob et al., "MicroRNA-101 inhibits human hepatocellular carcinoma progression through EZH2 downregulation and increased cytostatic drug sensitivity," Journal of Hepatology, vol. 60, no. 3, pp. 590-598, 2014.

[258] W. Li, S. Shen, S. Wu, Z. Chen, C. Hu, and R. Yan, "Regulation of tumorigenesis and metastasis of hepatocellular carcinoma tumor endothelial cells by microRNA-3178 and underlying mechanism," Biochemical and biophysical research communications, vol. 464, no. 3, pp. 881-887, 2015. 
[259] H. Okada, M. Honda, J. S. Campbell et al., "Inhibition of microRNA-214 ameliorates hepatic fibrosis and tumor incidence in platelet-derived growth factor C transgenic mice," Cancer Science, vol. 106, no. 9, pp. 1143-1152, 2015.

[260] X. Wang, Y. Ren, X. Yang et al., "miR-190a inhibits epithelialmesenchymal transition of hepatoma cells via targeting the long non-coding RNA treRNA," FEBS Letters, vol. 589, no. 24PartB, pp. 4079-4087, 2015.

[261] X. Yang, J. Ye, H. Yan et al., "MiR-491 attenuates cancer stem cells-like properties of hepatocellular carcinoma by inhibition of GIT-1/NF- $\kappa$ B-mediated EMT," Tumor Biology, vol. 37, no. 1, pp. 201-209, 2016.

[262] W. Z. Ding, Q. F. Ni, Y. T. Lu et al., "MicroRNA-497 regulates cell proliferation in hepatocellular carcinoma," Oncology Letters, vol. 11, no. 2, pp. 1081-1088, 2016.

[263] Y. Huang, J. Liu, L. Fan et al., "miR-663 overexpression induced by endoplasmic reticulum stress modulates hepatocellular carcinoma cell apoptosis via transforming growth factor beta 1," Oncotargets and Therapy, vol. 9, pp. 16231633, 2016.

[264] G. S. Chen, N. Zhou, J.-Q. Li, T. Li, Z.-Q. Zhang, and Z.-Z. Si, "Restoration of miR-20a expression suppresses cell proliferation, migration, and invasion in HepG2 cells," Oncotargets and Therapy, vol. 9, pp. 3067-3076, 2016.

[265] Q. ZHANG, S. ZHAO, X. PANG, and B. CHI, "MicroRNA381 suppresses cell growth and invasion by targeting the liver receptor homolog-1 in hepatocellular carcinoma," Oncology Reports, vol. 35, no. 3, pp. 1831-1840, 2016.

[266] N. Zhao, H. Sun, B. Sun et al., "miR-27a-3p suppresses tumor metastasis and VM by down-regulating VE-cadherin expression and inhibiting EMT: an essential role for Twist- 1 in HCC," Scientific Reports, vol. 6, no. 1, article 23091, 2016.

[267] Y. Wang, B. Sun, X. Zhao et al., "Twist1-related miR-26b-5p suppresses epithelial-mesenchymal transition, migration and invasion by targeting SMAD1 in hepatocellular carcinoma," Oncotarget, vol. 7, no. 17, pp. 24383-24401, 2016.

[268] W. Li, H. Dai, Q. Ou, G. Zuo, and C. Liu, "Overexpression of microRNA-30a-5p inhibits liver cancer cell proliferation and induces apoptosis by targeting MTDH/PTEN/AKT pathway," Tumor Biology, vol. 37, no. 5, pp. 5885-5895, 2016.

[269] S.-Y. Han, H.-B. Han, X.-Y. Tian et al., "MicroRNA-33a-3p suppresses cell migration and invasion by directly targeting PBX3 in human hepatocellular carcinoma," Oncotarget, vol. 7, no. 27, pp. 42461-42473, 2016.

[270] D. Zhou, X. Wang, Y. Wang et al., "MicroRNA-145 inhibits hepatic stellate cell activation and proliferation by targeting ZEB2 through Wnt/ $\beta$-catenin pathway," Molecular Immunology, vol. 75, pp. 151-160, 2016.

[271] M. Hu, M. Wang, H. Lu et al., "Loss of miR-1258 contributes to carcinogenesis and progression of liver cancer through targeting CDC28 protein kinase regulatory subunit 1B," Oncotarget, vol. 7, no. 28, pp. 43419-43431, 2016.

[272] H. Zhu, G. Wang, X. Zhou et al., "miR-1299 suppresses cell proliferation of hepatocellular carcinoma (HCC) by targeting CDK6," Biomedicine \& Pharmacotherapy, vol. 83, pp. 792797, 2016.

[273] X. Cui, Z. Li, J. Gao, P.-J. Gao, Y.-B. Ni, and J.-Y. Zhu, "Elevated CXCL1 increases hepatocellular carcinoma aggressiveness and is inhibited by miRNA-200a," Oncotarget, vol. 7, no. 40, pp. 65052-65066, 2016.
[274] R. A. Youness, H. M. El-Tayebi, R. A. Assal, K. Hosny, G. Esmat, and A. I. Abdelaziz, "MicroRNA-486-5p enhances hepatocellular carcinoma tumor suppression through repression of IGF-1R and its downstream mTOR, STAT3 and cMyc," Oncology Letters, vol. 12, no. 4, pp. 2567-2573, 2016.

[275] J. M. Lee, M. J. Heo, C. G. Lee, Y. M. Yang, and S. G. Kim, "Increase of miR-199a-5p by protoporphyrin IX, a photocatalyzer, directly inhibits E2F3, sensitizing mesenchymal tumor cells to anti-cancer agents," Oncotarget, vol. 6, no. 6, pp. 3918-3931, 2015.

[276] J. Liu, J. Yan, C. Zhou, Q. Ma, Q. Jin, and Z. Yang, "miR$1285-3 p$ acts as a potential tumor suppressor miRNA via downregulating JUN expression in hepatocellular carcinoma," Tumor Biology, vol. 36, no. 1, pp. 219-225, 2015.

[277] S. Chen, B. Liu, J. Xu et al., "MiR-449a suppresses the epithelial-mesenchymal transition and metastasis of hepatocellular carcinoma by multiple targets," BMC Cancer, vol. 15, no. 1, p. 706, 2015.

[278] D. Cai, K. He, S. Chang, D. Tong, and C. Huang, "MicroRNA-302b enhances the sensitivity of hepatocellular carcinoma cell lines to 5-FU via targeting Mcl-1 and DPYD," International Journal of Molecular Sciences, vol. 16, no. 10, pp. 23668-23682, 2015.

[279] L. Cao, B. Xie, X. Yang et al., "MiR-324-5p suppresses hepatocellular carcinoma cell invasion by counteracting ECM degradation through post-transcriptionally downregulating ETS1 and SP1," PLoS One, vol. 10, no. 7, article e0133074, 2015.

[280] H. Li, Q. Sun, B. Han, X. Yu, B. Hu, and S. Hu, "MiR-26b inhibits hepatocellular carcinoma cell proliferation, migration, and invasion by targeting EphA2," International Journal of Clinical and Experimental Pathology, vol. 8, no. 5, pp. 4782-4790, 2015.

[281] H. Zhang, Z. Feng, R. Huang, Z. Xia, G. Xiang, and J. Zhang, "MicroRNA-449 suppresses proliferation of hepatoma cell lines through blockade lipid metabolic pathway related to SIRT1," International Journal of Oncology, vol. 45, no. 5, pp. 2143-2152, 2014.

[282] X. X. He, A. Y. Guo, C. R. Xu et al., "Bioinformatics analysis identifies miR-221 as a core regulator in hepatocellular carcinoma and its silencing suppresses tumor properties," Oncology Reports, vol. 32, no. 3, pp. 1200-1210, 2014.

[283] W. Liu, C. Xu, H. Wan et al., "MicroRNA-206 overexpression promotes apoptosis, induces cell cycle arrest and inhibits the migration of human hepatocellular carcinoma HepG2 cells," International Journal of Molecular Medicine, vol. 34, no. 2, pp. 420-428, 2014.

[284] L. Yunqiao, H. Vanke, X. Jun, and G. Tangmeng, "MicroRNA-206, down-regulated in hepatocellular carcinoma, suppresses cell proliferation and promotes apoptosis," HepatoGastroenterology, vol. 61, no. 133, pp. 1302-1307, 2014.

[285] Y.-W. Dang, J. Zeng, R.-Q. He, M.-H. Rong, D.-Z. Luo, and G. Chen, "Effects of miR-152 on cell growth inhibition, motility suppression and apoptosis induction in hepatocellular carcinoma cells," Asian Pacific Journal of Cancer Prevention, vol. 15, no. 12, pp. 4969-4976, 2014.

[286] J. Zhang, H. Jin, H. Liu et al., "MiRNA-99a directly regulates AGO2 through translational repression in hepatocellular carcinoma," Oncogene, vol. 3, no. 4, article e97, 2014.

[287] W. Dai, C. Wang, F. Wang et al., "Anti-miR-197 inhibits migration in HCC cells by targeting KAI 1/CD82," Biochemical and Biophysical Research Communications, vol. 446, no. 2, pp. 541-548, 2014. 
[288] N. Zhao, R. Wang, L. Zhou, Y. Zhu, J. Gong, and S.-M. Zhuang, "MicroRNA-26b suppresses the NF- $\kappa$ B signaling and enhances the chemosensitivity of hepatocellular carcinoma cells by targeting TAK1 and TAB3," Molecular Cancer, vol. 13, no. 1, p. 35, 2014.

[289] Y. M. Liu, Y. Xia, W. Dai et al., "Cholesterol-conjugated let7amimics: antitumor efficacy on hepatocellular carcinoma in vitro and in a preclinical orthotopic xenograft model of systemic therapy," BMC Cancer, vol. 14, no. 1, p. 889, 2014.

[290] K. Zhu, Q. Pan, L. Q. Jia et al., "MiR-302c inhibits tumor growth of hepatocellular carcinoma by suppressing the endothelial-mesenchymal transition of endothelial cells," Scientific Reports, vol. 4, 2014.

[291] Q. Liu, Y. Xu, S. Wei et al., "miRNA-148b suppresses hepatic cancer stem cell by targeting neuropilin-1," Bioscience Reports, vol. 35, no. 4, 2015.

[292] W. Cui, Z. Huang, H. He et al., "MiR-1188 at the imprinted Dlk1-Dio3 domain acts as a tumor suppressor in hepatoma cells," Molecular Biology of the Cell, vol. 26, no. 8, pp. 14161427, 2015.

[293] D. Ma, X. Gao, Z. Liu, X. Lu, H. Ju, and N. Zhang, "Exosometransferred long non-coding RNA ASMTL-AS1 contributes to malignant phenotypes in residual hepatocellular carcinoma after insufficient radiofrequency ablation," Cell Proliferation, vol. 53, no. 9, 2020.

[294] T. Guo, C. Gong, P. Wu et al., "LINC00662 promotes hepatocellular carcinoma progression via altering genomic methylation profiles," Cell Death and Differentiation, vol. 27, no. 7, pp. 2191-2205, 2020. 